\title{
Identification of mineral components in tropical soils using reflectance spectroscopy and advanced spaceborne thermal emission and reflection radiometer (ASTER) data
}

\author{
Luiz Eduardo Vicente ${ }^{\mathrm{a}, \mathrm{b}, *}$, Carlos Roberto de Souza Filho ${ }^{\mathrm{a}}$ \\ a Geosciences Institute, University of Campinas, PO Box 6152, Campinas, São Paulo, Brazil \\ b Embrapa Satellite Monitoring, Campinas, São Paulo, Brazil
}

\section{A R T I C L E I N F O}

\section{Article history:}

Received 26 August 2010

Received in revised form 21 February 2011

Accepted 27 February 2011

Available online 11 April 2011

\section{Keywords:}

Reflectance spectroscopy

ASTER

Soil minerals

Tropical terrains

Hyperspectral

\begin{abstract}
A B S T R A C T
Soil characteristics provide important support for understanding transformations that occur in environmenta systems. Physical characteristics and chemical compositions of soils controlled by pedogenetic processes, climatic changes and land use imply different types of environmental transformations. Reflectance spectroscopy is an alternative soil mapping technique that uses spectral absorption features between visible (VIS) and short-wave infrared (SWIR) wavelengths $(0.3-2.5 \mu \mathrm{m})$ for determining soil mineralogy. Soil analysis by means of reflectance spectroscopy and orbital optical sensors have provided favorable results in mapping transformation processes in environmental systems, particularly in arid and semiarid climates in extra-tropical terrains. In the case of inter-tropical environments, these methods cannot be readily applied due to local factors such as lack of exposed regolith, high amounts of soil moisture and the presence of dense vegetation. This study uses Advanced Spaceborne Thermal Emission and Reflection Radiometer (ASTER) and reflectance spectroscopy data to map mineral components of soils covering a part of the state of São Paulo, Brazil, which could be linked to key aspects of environmental transformations in this tropical area (e.g., climate change, shifts in agriculture fronts, ph, and soil characteristics). We collected forty-two (42) soil samples at a depth of 0-20 cm, considering that this superficial layer corresponds to the highest correlation with soil properties detected by the ASTER sensor. These samples were measured using a FieldSpec FR spectrometer, and the derived spectra were interpreted for mineral composition. Interpretation was supported by X-ray diffraction analysis on the same samples. The spectral signatures were re-sampled to

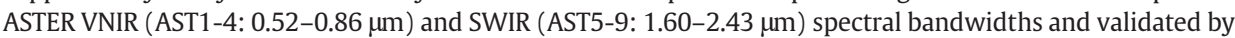
comparing reflectance spectra of field samples with those extracted from atmospherically corrected and calibrated ASTER pixels. The agreement between spectral signatures measured from soil samples and those derived from ASTER imagery pixels proved plausible, with $\mathrm{R}^{2}$ correlation values ranging from 0.6493 to 0.7886. This signifies that diagnostic spectral features of key minerals in tropical soils can be mapped at the spectral resolution of 9-band ASTER VNIR through SWIR reflectance. We used these spectral signatures as end-members in hyperspectral routine classifications adapted for use with ASTER data. Results proved possible the identification and remote mapping of minerals such as kaolinite, montmorillonite and gibbsite, as well as the distinction between iron-rich and iron-poor soils.
\end{abstract}

(C) 2011 Elsevier Inc. All rights reserved.

\section{Introduction}

A relatively less common approach in soil studies involves mapping pedological properties and their relation with environmental systems. Basically, this relation can be understood through physical and chemical processes associated with changes in vegetation cover, which result in the retention of greenhouse gasses and carbon fixation (e.g. $\mathrm{CO}_{2}, \mathrm{CO}, \mathrm{NOX}, \mathrm{N}_{2} \mathrm{O}$, and $\mathrm{CH}_{4}$ ), increased erosion, alteration of the nutrient cycle, increased turbidity of rivers, etc.

\footnotetext{
* Corresponding author at: Geosciences Institute, University of Campinas, PO Box 6152, Campinas, São Paulo, Brazil. Tel.: +55 19 32116200, +55 19 33085850; fax: + 55 1932116222

E-mail address: vicente@cnpm.embrapa.br (L.E. Vicente).
}

(Foley et al., 2005; Tilman \& Lehman, 2001). Therefore, soil characteristics of a defined environmental system are important indicators of its vulnerability, resistance and resilience to several multiscale processes that range from climatic changes on a global scale to land-use changes on the local scale.

Traditional pedological studies require ample field and laboratory analyses of samples collected from various landforms and at various depths. This type of approach is time consuming and requires large resource investments (Brady, 1989), which tend to increase as a function of project scale. Analysis of the spectral behavior of soils using reflectance spectroscopy (Ben-Dor et al., 1998) is an alternative approach to these traditional methods. It involves measuring electromagnetic radiation (REM) reflected from targets at different wavelengths, which results in particular spectral signatures (Clark, 
1999). The signatures are quantified according to the ratio between reflected energy (radiance) and incident energy (irradiance) on a defined target, the result of which measures reflectance (Clark, 1999).

Reflectance spectroscopy provides information about targets between visible (VIS) and shortwave infrared (SWIR) $(0.3-2.5 \mu \mathrm{m})$ wavelengths. Within this spectral range, some components such as iron oxides and hydroxides, organic materials, carbonates $\left(\mathrm{CO}_{3}\right)$, sulfates $\left(\mathrm{SO}_{4}\right)$, as well as typical cationic transitional vibrations present in phyllosilicates (e.g. $-\mathrm{OH}, \mathrm{Al}-\mathrm{OH}, \mathrm{Mg}-\mathrm{OH}$, and $\mathrm{Fe}-\mathrm{OH}$ bearing clay, mica and serpentine) can be identified (Ben-Dor et al., 1997; Chang et al., 2001; Grove et al., 1995; Stoner \& Baumgardner, 1981; Thompson et al., 1999).

The use of reflectance spectroscopy in the study of environmental systems is based on the spectral signatures of targets, principally those that can be reproduced considering the spectral resolution of current airborne and spaceborne multispectral and hyperspectral sensors. Reflectance spectra measured from samples can be used as end-members in Spectral Mixture Analysis (SMA) algorithms (Asner \& Lobell, 2000; Chabrillat et al., 2002) or in formulating simpler techniques for highlighting specific spectral features, such as band indices and band ratios (Arsenault \& Bonn, 2005). Both SMA and band ratios have generated good results, allowing for ample mapping of various soil types in different areas, especially in arid and semiarid regions (Morra et al., 1991; Shepherd \& Walsh, 2002). In the case of intertropical regions, dense vegetation cover, persistent cloud cover and poor exposure of regolith, rocks and soil make it difficult to use reflectance spectroscopy obtained from orbital sensors (Coleman et al., 1993). Besides those compiled for soils in Brazil, spectral data (spectral libraries) available for specific environmental conditions are scarce. However, we obtained important results from soil studies using local spectral signatures, often applied to broadband multispectral sensors such as Landsat TM/ETM+ (e.g. Madeira Netto et al., 1991; Nanni \& Demattê, 2006; Valeriano et al., 1995).

The Advanced Spaceborne Thermal Emission and Reflection Radiometer (ASTER) is a potential alternative spaceborne sensor for soil mapping, which possesses a broad potential yet to be explored for that purpose. ASTER provides spectral coverage in the visible (VIS) ( 0.52 to $0.69 \mu \mathrm{m}$ - bands 1 and 2 ) and near infrared regions (NIR) ( 0.78 to $0.86 \mu \mathrm{m}$ - band 3 ), and denser coverage in the shortwave infrared region (SWIR) (1.600 to $2.430 \mu \mathrm{m}$ - bands 4 to 9) (Abrams \& Hook, 1995) as compared to Landsat 5 and 7 TM/ETM+. Such trends in evolving instrument characteristics are an example of the general tendency towards increasing spectral resolutions of spaceborne remote sensing instruments, the maximum of which are currently restricted to hyperspectral sensors (e.g. AVIRIS, SpecTIR, Hyperion, Hymap, and CHRIS). Considering the low cost per scene (\$60 USD for non-educational and non-NASA affiliated users), high accessibility of ASTER data, and its unique technical characteristics, this sensor can greatly improve tropical soil mapping using information related to the spectral properties of its components (Galvão et al., 2005; Vicente et al., 2005).

Once the utility and limitations of ASTER data have been evaluated for the mapping of tropical soils, they may enhance the speed of production of soil maps both at the global scale and at the more useful scale, at a spatial resolution of individual land use and landscape features (e.g. $<30 \mathrm{~m}$ ). Hence, the purpose of this study is to analyze the spectral behavior of tropical soils in the VIS and SWIR regions using ASTER data supported by ground-truth based reflectance spectroscopy. Soil samples collected in the field were measured in the laboratory under artificial light in order to determine their spectral reflectance properties. The soil spectral signatures were convolved to ASTER's spectral resolution and compared to ASTER image pixels (converted to reflectance) at their respective sample collection sites. Each soil's spectral signature was used as endmember for mapping soil mineral components using a spectral mixture analysis (SMA) technique adapted for use with ASTER data.
We use SMA here to aid in the analysis of absorption features of the most dominant mineral components of the soils and to quantify the degree of correlation between the end-members verified in the field and those detected in the imagery. Finally, we assess ASTER's efficacy for effectively mapping these components remotely under the most optimum land cover and atmospheric conditions in our study area.

\section{Study area}

The study area is located in Assis, in the western region of the state of São Paulo, Brazil (Fig. 1). It covers $290 \mathrm{~km}^{2}$ (IBGE/CIM, 2004) of the Paraná sedimentary basin in the Western São Paulo Plateau. It is part of the Western Central and Residual Plateaus of Marília and São Carlos (basaltic cuestas) with altitudes that range between 300 and $700 \mathrm{~m}$ (IPT, 1981). Three litho-structural units comprise this area: the Adamantine Formation to the NE, the Marília Formation to the NW (high-altitude areas) and the Serra Geral Formation, that occupies sectors along the Paranapanema river in lower terrains (IAC, 1999).

The study area has a reasonable variety of landforms and lithologic types as well as soils that belong to different soil orders. According to previous surveys performed in the study area (IAC, 1999) (Fig. 2), we divided soil types as follows: Oxisols (Ox) (LV78/LV1); Ultisols (PVA2/ PVA10/PVA5) (Ul); Lithic Orthents (LO) (RL4) and Alfisols (Al) (NV1). Also, since the 19th century this site has gone through intense anthropogenic modification consisting of different types of land use: predominantly pastural intermingled with patches of natural vegetation. Its main characteristics are the small size and heterogeneous distribution of use and types of landscape parcels. The Assis Ecologic Station (AES) is a preserved area where remnants of tropical savanna and natural vegetation predominate. The AES and surrounding preserved areas served as baseline for collecting and analyzing vegetation and soil spectral signatures in least disturbed portions of this study (Fig. 2).

Due to its geographical location, the region's climate is typically tropical with an average temperature of $22^{\circ} \mathrm{C}$, and an annual precipitation around $1440 \mathrm{~mm}$. It presents two well-defined seasons: a warm, rainy period from October to March, with a monthly mean pluviometric range between 135.5 and $236.5 \mathrm{~mm}$, and a period of drought and lower temperatures, with a pluviometric range between 99.5 and $34.0 \mathrm{~mm}$.

\section{Materials}

The ASTER scene used in this investigation was obtained at the $1 \mathrm{~B}$ processing level from the USGS EROS Data Center (EDC), with radiometric and geometric corrections previously applied. The image was acquired on September 19, 2003, within the local drought season, in order to minimize vegetation cover and soil moisture, and to maximize the exposure of bare soils. Soil moisture tends to specifically reduce the spectral contrast of soils (Ben-Dor et al., 1998), a common situation for tropical terrains.

The collection and interpretation of the imagery's end-members were guided by the following maps of the study area: (i) pedological map at a 1:500,000 scale (IAC, 1999) (Fig. 2); (ii) geomorphologic map at a 1:500,000 scale (IPT, 1981); (iii) geologic map at a 1:500,000 scale (IPT, 1981); (iv) vegetation cover map of the São Paulo state at a 1:50,000 scale (SMA - Secretaria do Meio Ambiente - (IF) Instituto Florestal/Biota-FAPESP, 2002); and (v) cartographic base maps at a $1: 100,000$ scale (IBGE, 2004).

Forty-two (42) sites were preselected in the imagery, and visited in the field. Twenty-five (25) samples were collected, including all representative soil types contained within our study area (Fig. 2). The disposition of the sites also helped to obtain a satisfactory variation of mesoscale soil properties, considering the size of the sampled area and its varying geomorphology. We collected each sample at a depth of 0 to $20 \mathrm{~cm}$. Brady (1989) showed that such depths show the highest 


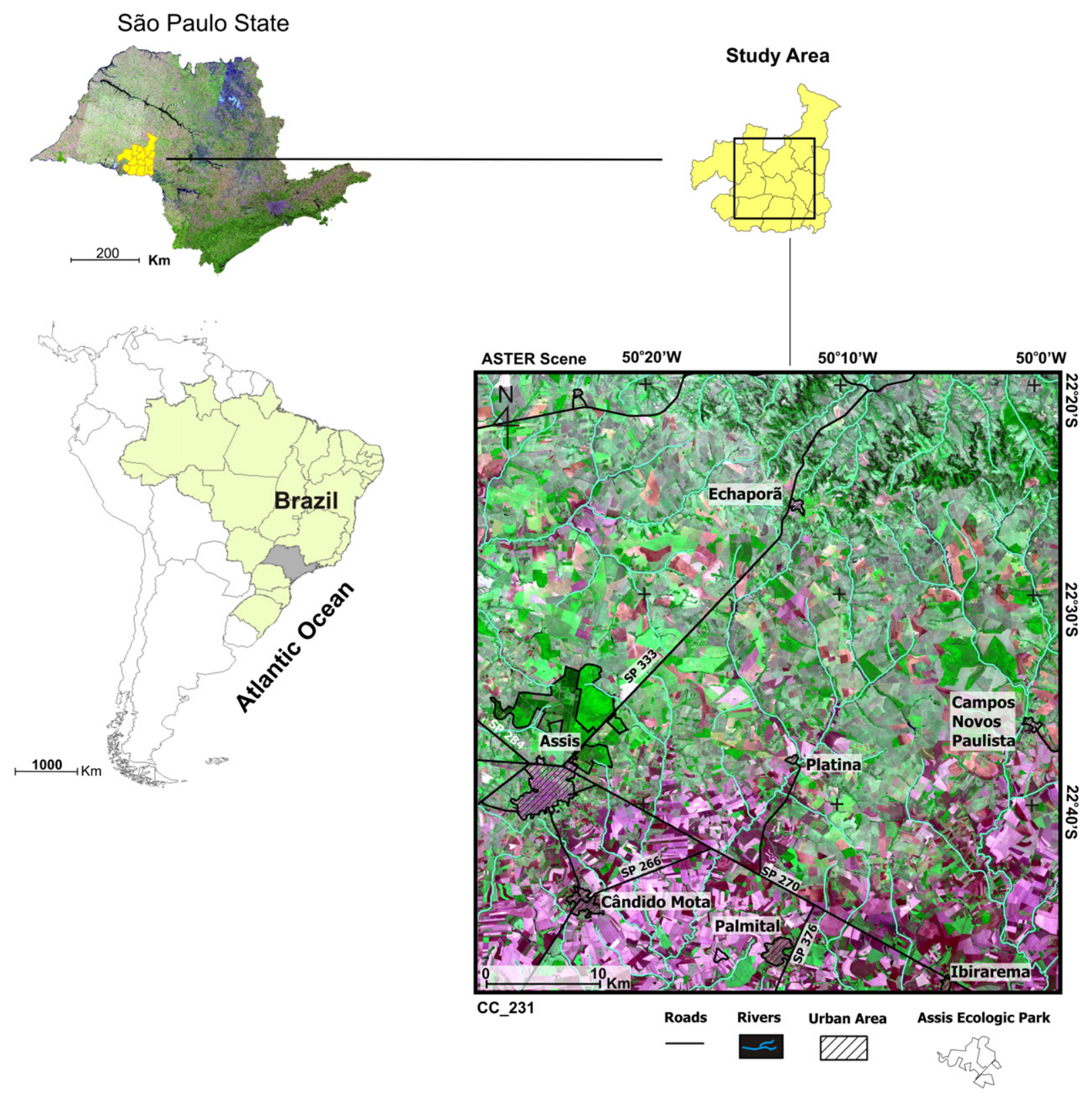

Fig. 1. Location map of the study area.

correlation with data captured by remote sensors, generally clay, silicates, iron and aluminum oxides/hydroxides.

\section{Methods}

\subsection{Preprocessing of ASTER data}

The original ASTER (Level 1B) scene data were initially corrected for crosstalk effects using the automated Crosstalk Correction Software (ERSDAC, 2001). This crosstalk effect is due to the dispersion of incident light in band AST4, which is diffused to the focal plane of other SWIR bands, causing the appearance of noise and related anomalies at the interface of land and water (Iwasaki \& Tonooka, 2005). The data were subsequently atmospherically-corrected using the Moderate Resolution Atmospheric Radiance and Transmittance Model (MODTRAN), and converted to reflectance. We considered the following regional parameters and image acquisition conditions: (i) mean elevation of the study region, (ii) platform altitude, (iii) data acquisition date and time, (iv) aerosol estimate (visibility), (v) area coordinates, (vi) water vapor estimate in the atmosphere, and (vii) atmospheric model (tropical) (ACORN, 2002).

Collectively, these preprocessing procedures were of critical importance for calibrating pixels within the ASTER imagery to spectral signatures comparable to those obtained from field samples. Spatial re-sampling of the SWIR bands was performed by artificially increasing their resolution to $15 \mathrm{~m}$, which made it possible to work with all nine VNIR-SWIR bands simultaneously.

\subsection{Interpretation of spectral signatures of minerals in soils}

Hematite $\left(\mathrm{F}_{2} \mathrm{O}_{3}\right)$, goethite $(\mathrm{FeOOH})$, kaolinite $\left(\mathrm{AL}_{2}\left(\mathrm{Si}_{2} \mathrm{O}_{5}\right)(\mathrm{OH})_{4}\right)$, montmorillonite $\left(\mathrm{AL}_{4} \mathrm{Si}_{8}(\mathrm{OH})_{4} \mathrm{H}_{2} \mathrm{O}\right)$ and gibbsite $\left(\mathrm{Al}-\mathrm{OH}_{3} \mathrm{~S}_{\mathrm{i}}\right)$ are common minerals in tropical soils due to their close association with leaching and precipitation processes (Allen \& Hajek, 1989). Although montmorillonite in particular is more widespread in semiarid regions, it is associated with poorly drained soils (EMBRAPA, 1999) in intertropical environments. Therefore, determining the presence and quantity of these minerals is fundamental for estimating 


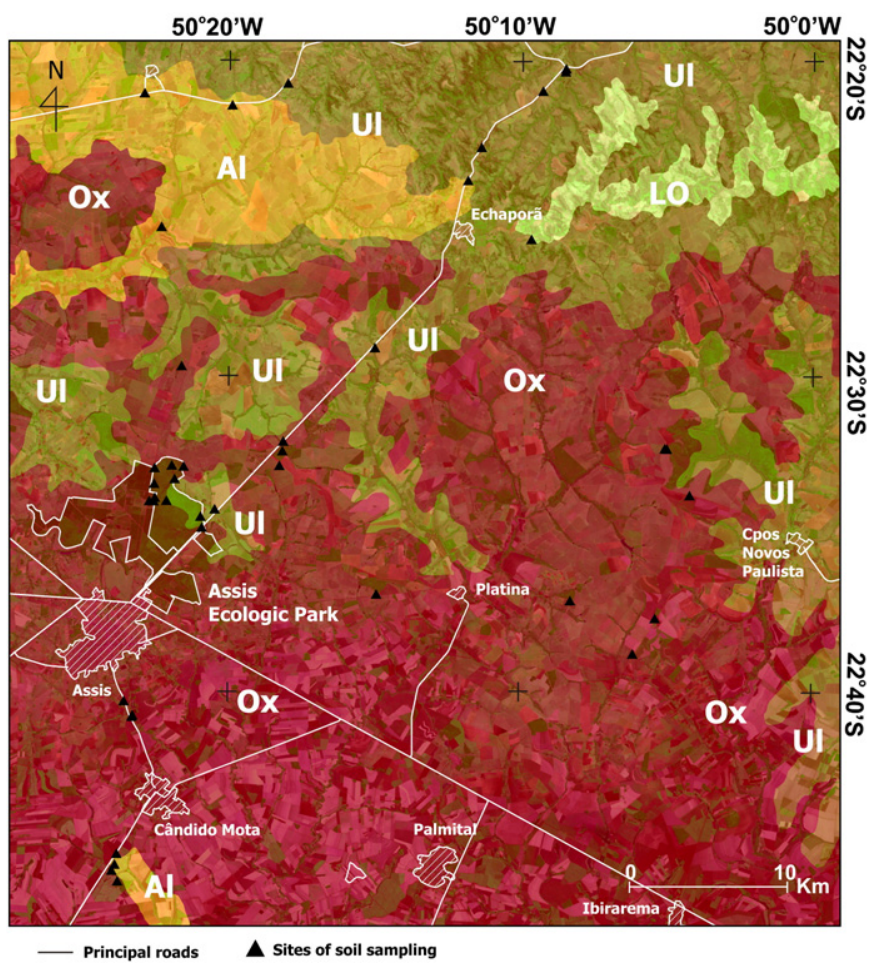

Fig. 2. Soil map and sites of soil sampling. A false color composite of ASTER bands 231 $(\mathrm{RGB})$ is displayed in the background. $\mathrm{Ox}=$ Oxisols. $\mathrm{Al}=$ Alfisols. $\mathrm{UI}=$ Ultisols.

soil fertility and fragility, and other important physical and hydrological properties such as storm-induced sealing/crusting, permeability, runoff and erosion potential (Poesen \& Nearing, 1993; Sumner \& Stewart, 1992).

Here, spectral analyses of the soil samples are used for extracting such relevant mineralogical information. Reference spectra from the United States Geological Survey (USGS) spectral library (Clark et al., 1993) were used for comparative analysis and spectral classification of the ASTER data. Iron oxides and hydroxides (hematite and goethite) are highly mobile when exposed to physical and chemical changes. These minerals show charge transfer and $\mathrm{Fe}^{3+}$ crystal field bands between the VNIR wavelength ranges. Hematite displays diagnostic absorption features at about $0.53,0.63$ and $0.88 \mu \mathrm{m}$, whereas goethite's are at about $0.48,0.67$ and $0.94 \mu \mathrm{m}$. The $0.54 \mu \mathrm{m}$ and $0.48 \mu \mathrm{m}$ charge transfer absorptions imply tonal variations of red and orange for hematite and goethite respectively (Hunt et al., 1971) (Fig. 3)

Kaolinite and montmorillonite reveal typical hydroxyl $\left(\mathrm{OH}^{-}\right)$and water absorption features centered around 1.4, 1.9 and 2.205 $\mu \mathrm{m}$. The $1.4 \mu \mathrm{m}$ features are the first overtones of the $\mathrm{OH}^{-}$stretches. The combination of $\mathrm{Al}-\mathrm{OH}$ bend plus $\mathrm{OH}^{-}$stretch causes the $2.205 \mu \mathrm{m}$ absorptions. The $1.9 \mu \mathrm{m}$ feature is most pronounced in expandable clay minerals such as montmorillonite, and is due to the water overtone (Hunt \& Salisbury, 1971). Gibbsite, an aluminum hydroxide mineral $\left(\mathrm{Al}-\mathrm{OH}_{3}\right)$, presents multiple features centered at $1.4 \mu \mathrm{m}$, but yields a particularly diagnostic absorption feature at $2.265 \mu \mathrm{m}$ (Hunt et al., 1971) (Fig. 3).

Dark, carbon compounds derived from the decomposition of organic matter (humines, fulvic acids, and humic acids) are additional soil components that need to be considered during spectral analysis, due to their particulate behavior in intimate mixtures and coatings (Ben-Dor et al., 1997; Clark, 1999). These components influence the entire VNIR-SWIR spectrum, with only a few percent of dark grains in the soil significantly reducing the reflectance, much more than their

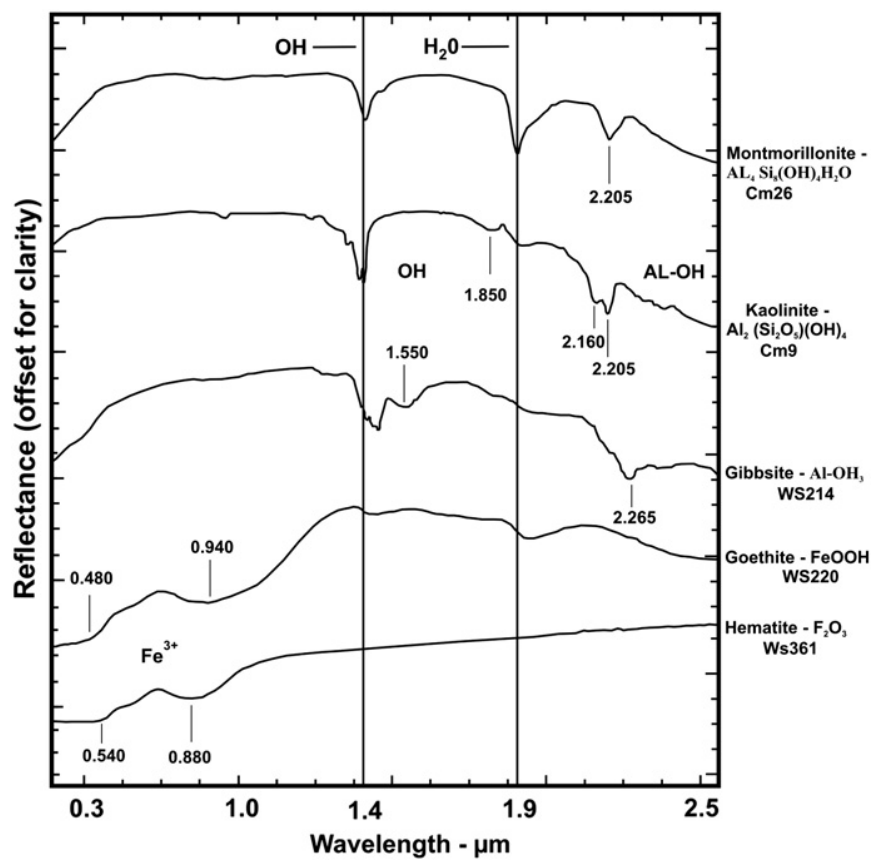

Fig. 3. Spectra of main mineral components of tropical soils considered in this study (source: USGSLib). Reflectance values were rescaled to improve visualization.

weight fraction would suggest in such intimate mixtures (Clark, 1999). An estimate of the influence of carbon compounds and that of colloid interlayer water in the soil (i.e. a molecular mixture, Clark, 1999 ) is exceptionally important in tropical regions because of their dependence and covariation with climatic factors (e.g. humidity and chemical weathering). These can alter the spectra of the mineral components, such as iron oxides and hydroxides, clay minerals, etc. (Madeira Netto et al., 1991).

\subsection{Reflectance spectroscopy: analysis of soil samples' end-members}

We submitted the ASTER data to the Minimum Noise Fraction transformation (MNF) (Boardman \& Kruse, 1994; Green et al., 1988) and Pixel Purity Index (PPI) (Boardman et al., 1995) procedures in order to select end-members. These procedures are essential for reducing spectral and spatial dimensionality of data respectively. The MNF uses two opposite orthogonal linear transformations based on Principal Components Analysis (PCA) to reduce an interband correlation and isolate noise: (i) the first transformation estimated the noise using a covariance matrix, and (ii) the second transformation is a typical PCA that estimates the data dimensionality using eigenvalue bands. In the case of ASTER, the MNF reduction in data dimensionality is needed not because of the quantity of bands, since it is not a hyperspectral sensor, but as a refinement of possible sets of end-members that can be separated and expressed in the set of MNF images under reduction. Also, this procedure aims to create a dataset with isotropic, unit variance noise, which is a requirement for the successful application of the Mixture-Tuned Matched Filtering (MTMF) algorithm. Most usually the pixel values in the multispectral/hyperspectral images are a spectral mixture from several materials, and an end-member dataset is established to determine the pixel's "spectral purity". The PPI procedure (convex geometry Boardman, 1993) reprojects randomly and repeatedly a pixel's array into an n-dimensional scatterplot arrangement using a vector unit, and the pixels in the extreme position in each projection are recorded. Therefore pure pixels are also called end-members. The result is a new dataset in which the pixels marked as extreme a greater number of times are considered pure, and the counting decreases when the mixed pixel count increases. 
We collected twenty-five (25) samples, including all representative soil types contained within our study area. Our choice of areas for colleting soil samples was based on analog sites between field areas (forty-two preselected areas - item 3) and the same pixels indicated as soil end-members in the ASTER image. This approach decreases the redundancy of the characteristics of field soil samples and provides an isonomic dataset arrangement for the comparison of spectral characteristics from ASTER and soil samples' spectral signature. The spectral reflectance of soil samples was measured in the laboratory using a FieldSpec Full-Resolution $(0.350-0.250 \mu \mathrm{m})$ portable spectrometer (ASD, 1999). The samples underwent a natural drying process in order to reduce the effects of humidity, which may cause nonlinear oscillations of soil spectra (Lobell \& Asner, 2002). Each sample was measured twice using a $90^{\circ}$ variation between the illumination source and the spectrometer's optical input. A mean value was obtained for each reading to balance the disposition of surface textural effects in relation to the FieldSpec FR instantaneous field of view (ASD, 1999). A normalization function was applied to all spectra to remove the background (i.e. continuum - Clark, 1999; Clark \& Roush, 1984), thus enhancing spectral absorption features and making them more comparable to each other and to those from other sources, such as ASTER image spectra (Fig. 4).

We identified several characteristics that are representative of the soils found in the study area, forming five distinct groups represented by spectra of key soil samples highlighted in Fig. 4. In these groups, a more accentuated presence of iron-bearing minerals was detected in Alfisols and Oxisols, with ample features around 0.520 and $0.890 \mu \mathrm{m}$ (Fig. 4) respectively. Both features were reciprocally proportional and related to the presence of ferric iron $\left(\mathrm{Fe}^{3+}\right.$ ) (Hunt et al., 1971). Therefore, an accurate detection of these $\mathrm{Fe}^{3+}$-bearing minerals should take into consideration these features, giving priority to the wavelength region above $0.7 \mu \mathrm{m}$ in the design of future sensors. The reflectance scores observed in the Alfisols and Oxisols sampled indicated predominance of hematite over goethite. Samples A4, A14 (Alfisols) and A5, A6, and A21 (Oxisols) show a reddish color and signatures with intense absorption features in VNIR-SWIR, all typical of hematite-rich soils. The VNIR features found at $0.88 \mu \mathrm{m}$ are associated with the weathering of the basaltic rocks that comprise the bedrock in this region. A wealth of earlier studies also indicated that these features are typical of hematite derived from the alteration of basaltic rocks into tropical soils (e.g. Epiphanio et al., 1992; Stoner et al., 1991). Another indicator of the elevated ferric-iron content in the soils of the study area, particularly in the Alfisols, is the low reflectance throughout all wavelengths (Fig. 4). This characteristic is also observed and discussed by Stoner and Baumgardner (1981). The proportion of iron decreases in all other Ultisol soil samples (A9 and A24 - Fig. 4) and the spectral features related to its presence are practically nonexistent in the spectra of Lithic Orthents soils (A13, A17, and A28 - Fig. 4).

In most samples, the presence of clay minerals is highlighted by absorption features between 2.16 and $2.20 \mu \mathrm{m}$ due to the presence of hydroxyl groups $\left(\mathrm{OH}^{-}\right)$(Hunt \& Salisbury, 1971). Such clays are formed by the decomposition of mafic minerals, vitric components and feldspars, which are primary components of basaltic rocks. In Lithic Orthents (A17, A13, and A28 - Fig. 4) samples, the distinct absorption bands at 1.4 and $1.9 \mu \mathrm{m}$ are associated with a single feature at $2.205 \mu \mathrm{m}$ and a mild concavity at around $0.61 \mu \mathrm{m}$, thus revealing the presence of phyllosilicates with 2:1 layered-structures (i.e. minerals that have an octahedral sheet sandwiched between two tetrahedral sheets), in this case a characteristic of montmorillonite (Hunt \& Salisbury, 1971). Even with the predominance of montmorillonite, the A17 sample reveals a smooth spectral feature at $2.165 \mu \mathrm{m}$, probably due to the presence of kaolinite. The presence of montmorillonite in sandy soil is uncommon, but it has been identified in association with the Botucatu arenite (Demattê \& Holowaychuck, 1977). Montmorillonite and kaolinite are distinguished by the presence of hydroxyl and water molecules in their structure, which are directly associated with $1.4-\mu \mathrm{m}$ and $1.9-\mu \mathrm{m}$ absorption bands (Kruse et al., 1991). The 1.9- $\mu \mathrm{m}$ water-absorption band is typically stronger in montmorillonite due to its water-expandability characteristics. Hydroxyl and its link with metals such as aluminum create different symmetries of the absorption features of these clays, both centered at $2.200 \mu \mathrm{m}$. As a result, kaolinite yields a doublet-shaped spectral absorption feature, while montmorillonite yields a broader singlet-shaped spectral absorption feature (Hunt \& Salisbury, 1971).

The presence of gibbsite was only found in the Alfisol A4 sample (Fig. 4), and is associated with intense soil exposure resulting from agricultural land use. This mineral was diagnosed on the basis of its typical 2.264- $\mu \mathrm{m}$ feature, and displays a characteristic inflection previously verified by Madeira Netto et al. (1991) in well-developed tropical soils. Lithic Orthents (A13, A17, and A28 - Fig. 4) soils display a sandy texture as well as low iron contents. Consequently, these samples display high reflectance and sharper absorption features in SWIR. Collectively, these spectral variations found within our soil reflectance spectra permit the reclassification of soil subgroups.

\subsection{Validation of soil reflectance spectroscopy using X-ray Diffractometry (XRD)}

The five representative key samples selected in the previous step summarize the main characteristics of the soils in the study area (i) samples with either highest or lowest iron content; (ii) samples containing kaolinite; (iii) samples containing montmorillonite; (iv) samples containing gibbsite; and (v) samples with coarse texture (i.e. sandy soil) (Fig. 5) -, and were to undergo X-ray Diffractometric (XRD) analysis on total soil fractions using a Siemens Kristalloflex Diffraktometer (Fig. 5). While differences in particle size and degree of crystallinity strongly affect the intensity of the diffraction peaks, quantitative measures using XRD are difficult to achieve. Besides, the spectral measurements are not always proportional to the intensity of XRD peaks. Spectral reflectance measurements can be affected by abundant coating on the surface of the sample, thus resulting in greater depths of diagnostic features. The same sample may not yield proportionally intense X-ray peaks, because it may not be as abundant volumetrically as it is in the surface area (Buckingham \& Sommer, 1983). However, our goal was not to establish quantitative measures in this study, but to use the XRD results to assess the samples' mineralogy, and for further cross comparison with the mineralogy determined by interpretative reflectance spectroscopy in order to validate its presence in the study area, and its relative abundance.

The XRD consistently detected the presence of quartz in all samples due to its ubiquitous presence in the larger soil fractions. XRD analysis of sample A13 (LO) (Fig. 5a) - characterized by high reflectance and complete absence of iron oxides - showed a predominance of quartz, confirmed by the elevated intensity of its characteristic peaks $(\mathrm{d}=3.351)$ (Fig. $5 \mathrm{~b})$. XRD indicated a higher proportion of kaolinite in sample A6 (Ox) $(d=7.185)$ (Fig. 5e) than in other samples. Spectra yielded from this sample showed a doublet formed by relatively subtle absorption features at 2.165 and $2.205 \mu \mathrm{m}$ (Fig. 5a), which denotes the presence of kaolinite. Magnetite, detected by XRD in the same sample, was responsible for the overall low reflectance and inhibition of a more conspicuous appearance of these kaolinite absorption features in the SWIR range (e.g. Clark, 1999) (Fig. 5a).

The variations in the levels of iron oxide were evident in samples A14 (A1) and A21 (Ox). Spectral inflections at around 0.54 and $0.88 \mu \mathrm{m}$ (Fig. 5a) were observed in sample A14, and these are related to the greater quantity of hematite indicated by XRD $(\mathrm{d}=2.7078$ and $\mathrm{d}=4.5193$ ) (Fig. 5f). Sample A21 is hematite-free and shows only traces of goethite (Fig. 5d).

Montmorillonite appears to occur interstratified with illite in samples with a more sandy constitution - samples A13 (LO) and A21 


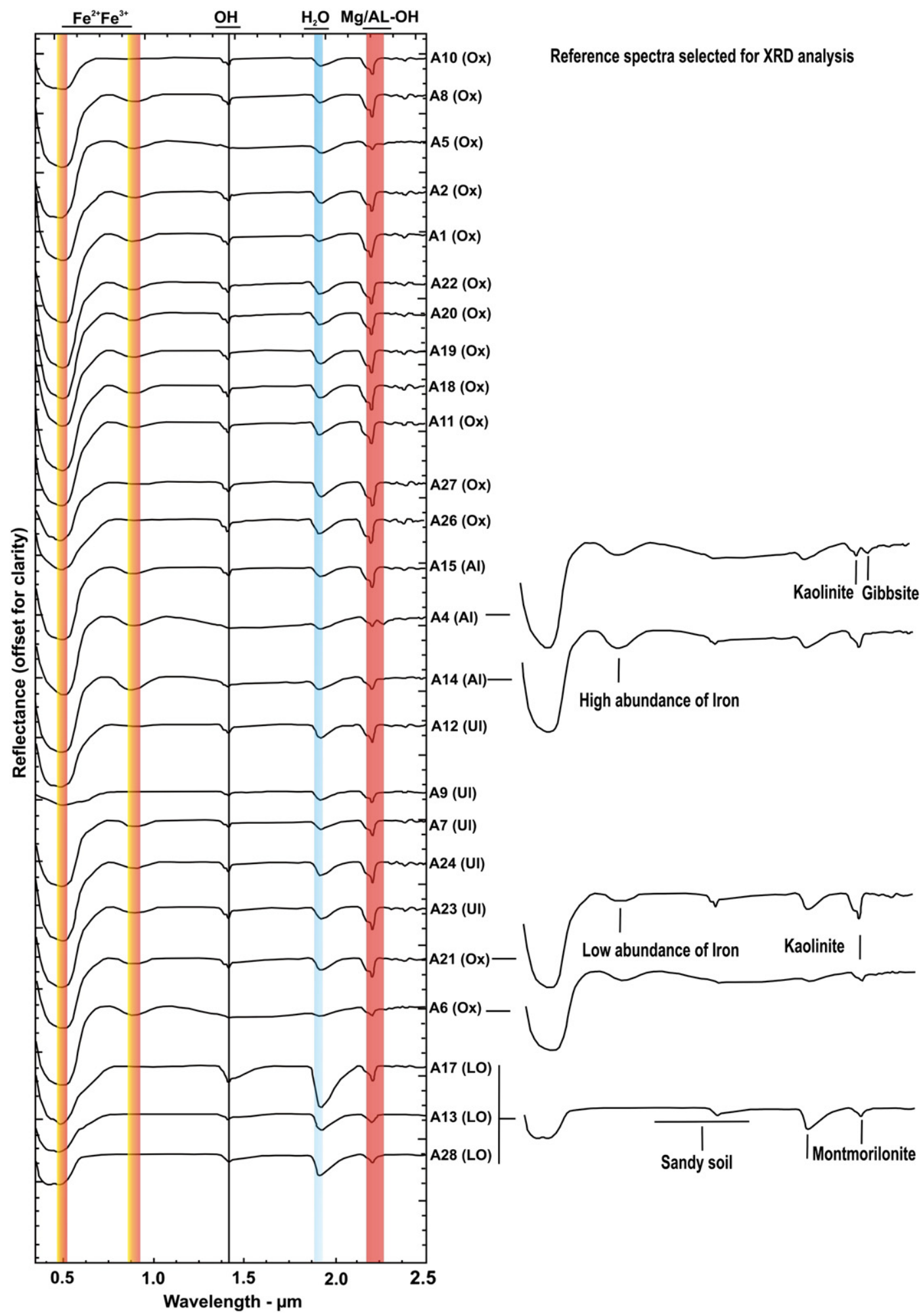

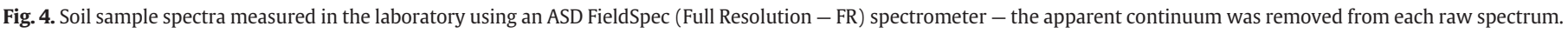

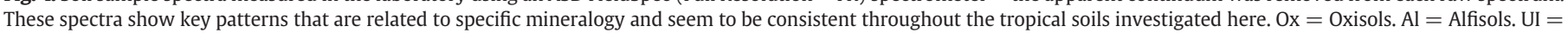
Ultisols. $\mathrm{LO}=$ Lithic Orthents.

(Ox), Fig. 5b and d. Its peak position $(d=9.472)$ in the diffractogram signifies a large basal amplitude of molecules of the constituent minerals, characteristic of clayey 2:1 minerals, whereas the interplanar distance between peaks indicates an unaltered soil, with minerals that still conserve their crystallographic structure (i.e. highly ordered) (Sawhney, 1989). The spectral signatures yielded for samples A13 and A21 suggest a variation in the presence of montmorillonite, and in its relative abundance, also expectedly verified by XRD. Both samples display absorption bands centered at $1.9 \mu \mathrm{m}$ and $2.205 \mu \mathrm{m}$ that are akin to the presence of montmorillonite (Fig. 5a). However, sample A13 is featureless at $2.165 \mu \mathrm{m}$, which indicates that it is exclusively composed of montmorillonite; 


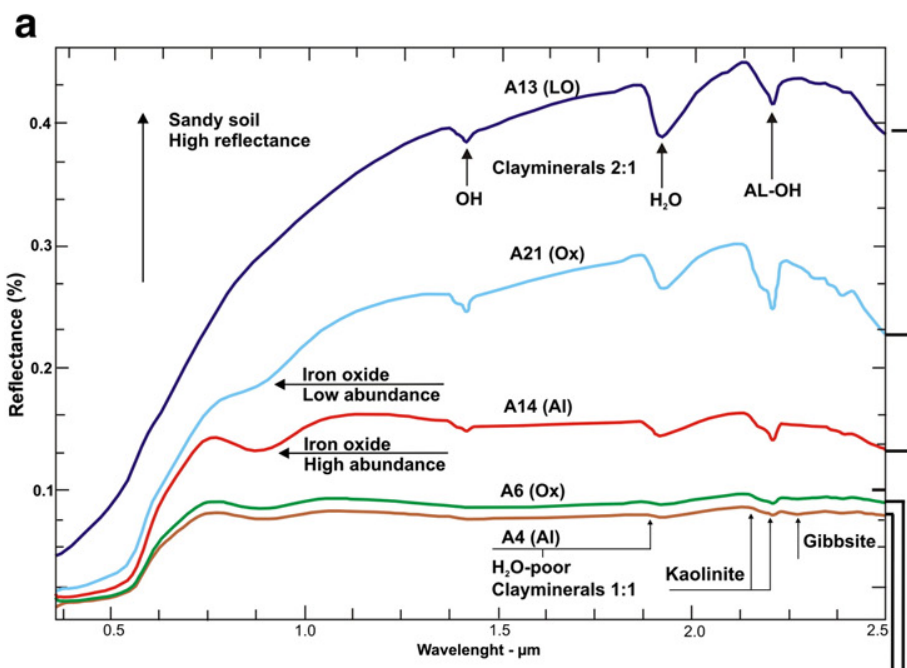

b

\section{C}

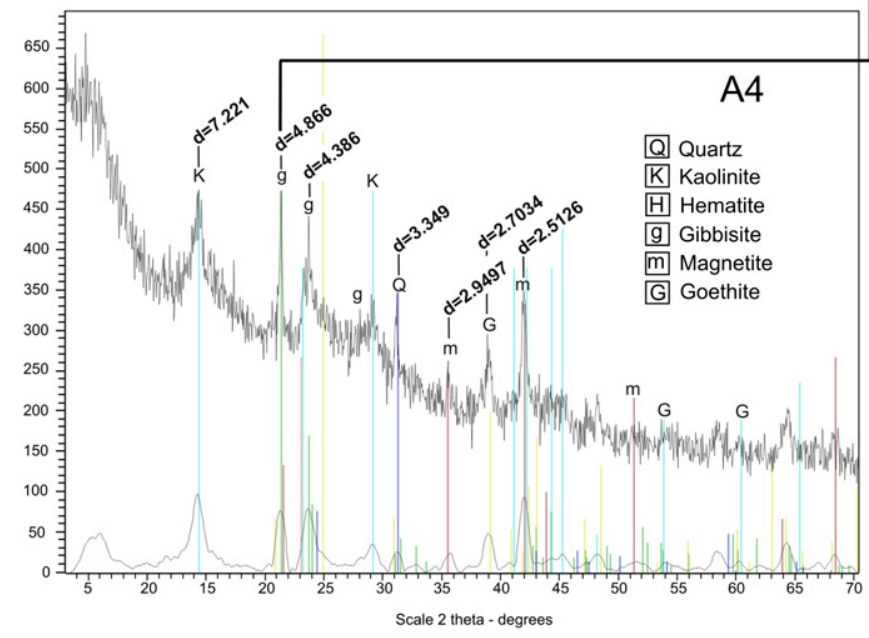

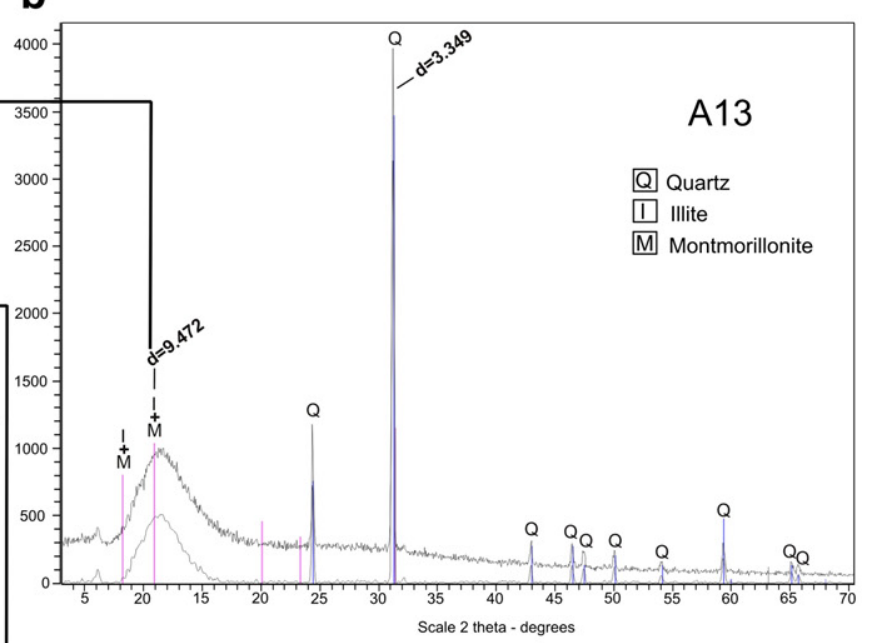

d

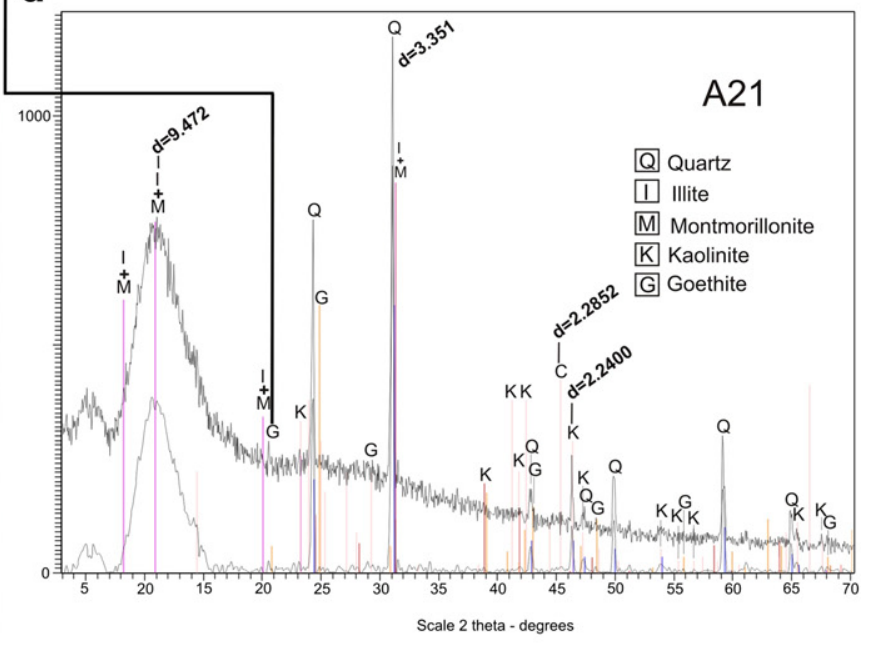

e

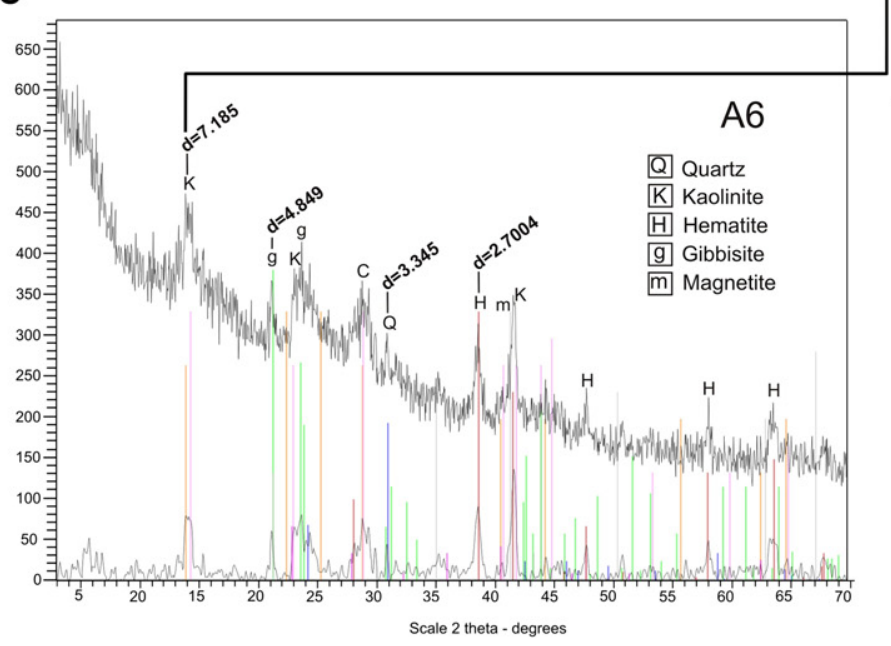

$\mathbf{f}$

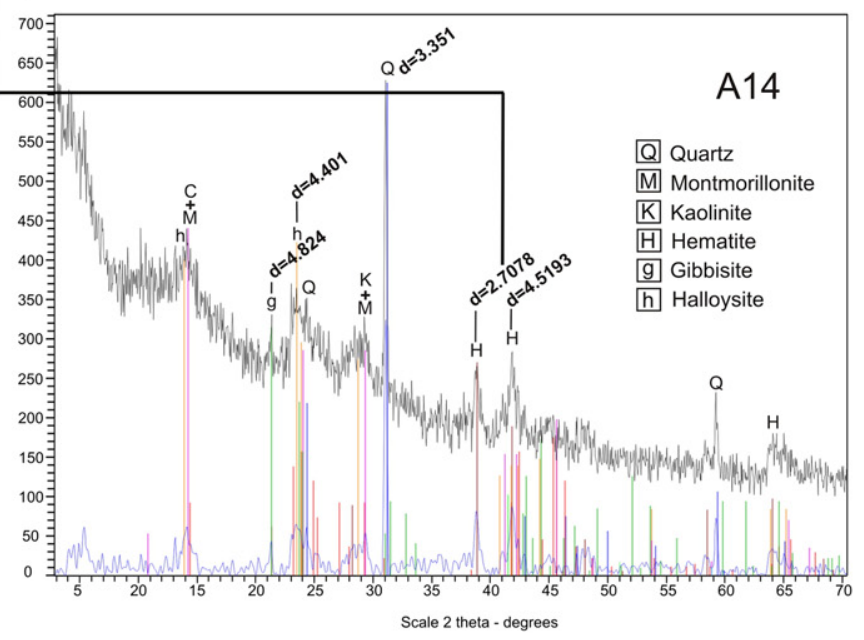

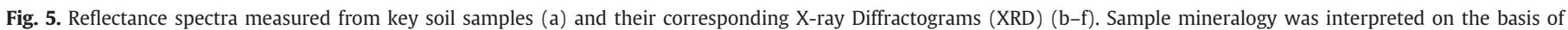

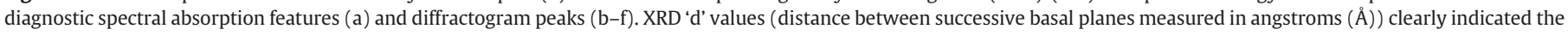
presence of a range of minerals, most of which are equivalently recognized by reflectance spectroscopy. Ox $=\mathrm{Oxisols}$. Al $=\mathrm{Alfisols}$. UI $=\mathrm{Ultisols}$. LO $=\mathrm{Lithic}$ Orthents.

whereas sample A21 displays features at $1.9 \mu \mathrm{m}, 2.205 \mu \mathrm{m}$ and $2.165 \mu \mathrm{m}$ simultaneously, which indicates a mixture of kaolinite and montmorillonite.
Gibbsite was detected in sample A4 (A1) because of its characteristic XRD peaks ( $d=4.866$ and $d=4.386$ ) (Fig. $5 c$ ), and its archetypal absorption feature at $2.265 \mu \mathrm{m}$ (Fig. 5a). 


\section{Results and discussion}

\subsection{Resampling soil reference spectra for ASTER spectral analysis and unconstrained unmixing}

Considering the higher spectral resolution of the ASD lab instrument, XRD-analyzed soil samples clearly display spectral signatures that allow the identification of key minerals and their relative proportions. In order to verify how much of this is reproducible at the spectral resolution of multispectral sensors, soil spectra were convolved to ASTER's VNIR-SWIR bandpass functions (bands 1 to 9 ).

Soils containing higher (A14) and lower levels of iron (A21) display diagnostic modifications of reflectance values and feature depths around $0.880 \mu \mathrm{m}$. The variation in iron content becomes evident as the angle between features of adjacent spectra changes, thus indicating ever-increasing absorption (i.e. reduction in reflectance) centered at $0.88 \mu \mathrm{m}$. This behavior is well mapped by ASTER bands AST1 $(0.52-060 \mu \mathrm{m})$, AST2 $(063-0.69 \mu \mathrm{m})$ and AST3 $(0.78-$ $0.86 \mu \mathrm{m}$ ) in particular (Fig. 6). ASTER spectral coverage in the VNIR range is similar to that provided by the ETM+ and TM sensors

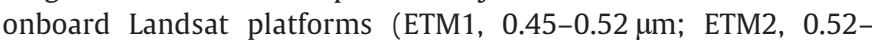
$0.60 \mu \mathrm{m}$; ETM3, 0.63-0.69 $\mu \mathrm{m}$; and ETM4, 0.77-0.90 $\mu \mathrm{m}$ ), except for the lack of a band covering the visible blue wavelengths. As ETM3/ ETM1 band ratios proved successful in detecting ferric iron at the surface (Fraser, 1991), the same should be feasible using an ASTER band ratio AST2/AST1.

Spectra of soils containing montmorillonite (A13) and kaolinite (A6) show distinct absorption features at $2.205 \mu \mathrm{m}$ (exclusively) and at 2.165 and $2.205 \mu \mathrm{m}$ (simultaneously) respectively (Fig. 7a). ASTER spectral characteristics in the SWIR region potentially allow for these two minerals to be mapped separately. Considering USGS spectra, montmorillonite shows a sharp, single absorption centered at band AST5 (2.145-2.185 $\mu \mathrm{m})$, whereas kaolinite's doublet forms either a shallow or a slightly inclined line between bands AST5 and AST6 $(2.185-2.225 \mu \mathrm{m})$ (Fig. 7a). Similar features are observed in soil samples of the study area (Fig. 7b), revealing an analogous behavior among reference minerals and soils, thus allowing for their potential discrimination and mapping using ASTER imagery.

Particularly in the case of the diagnostic features of kaolinite, a doublet feature is not always perfectly defined due to the level of disorder in the crystalline structure of this mineral (Crowley \& Vergo, 1988; Ducart et al., 2006; Senna et al., 2008; Velde, 1992). In this case,

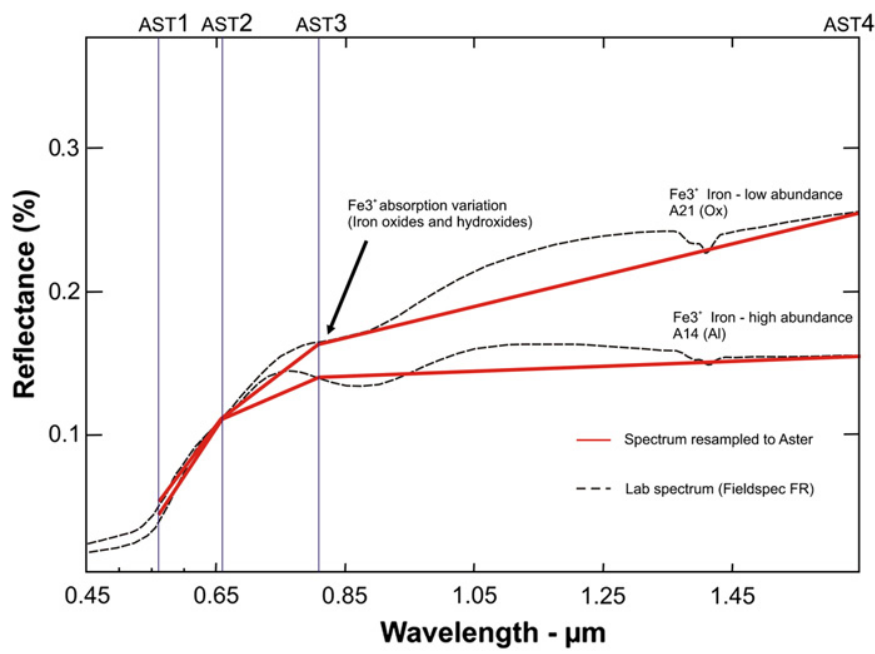

Fig. 6. Soil reference spectra measured in the laboratory and resampled to ASTER's VNIR-SWIR (nine bands) spectral resolution. Variations in iron levels are depicted by modifications of reflectance values and feature depths around $0.520 \mu \mathrm{m}$ and $0.880 \mu \mathrm{m}$. its behavior may be associated with weathering and processes of soil formation, which can be indicated by the basal distance between intense peaks of XRD measurements. Therefore, a variation in the depth of related spectral absorption bands is also an important indicator of mineral alterations in the soil.

A typical absorption feature of gibbsite, centered at $2.265 \mu \mathrm{m}$, was identified in sample A4 (drawn lines - Fig. 4). This feature is caused by the presence of aluminum molecules and their linkage with hydroxyls $(\mathrm{Al}-\mathrm{OH})$, giving origin to a double feature that is reproduced at bands AST6 $(2.185-2.225 \mu \mathrm{m})$ and AST7 (2.235$2.285 \mu \mathrm{m}$ ) (continuous line - Fig. 8a). The sample exhibits low reflectance due to an abundant quantity of ferric iron (e.g. Clark, 1999). However, the features are evident in continuum-removed spectra (Fig. 8b). Thus, variation in depth and displacement of features in bands AST6 and AST7 may provide important information about the presence and quantity of gibbsite in soils.

\subsection{Soil reflectance spectra vs. ASTER image spectra}

The capacity of an orbital sensor for mapping spectral variations defined in the laboratory on the basis of field samples is restricted by its spectral and spatial resolution. In the case of ASTER, the spatial resolution extends up to $15 \mathrm{~m}$ - one of the best in the multispectral sensor category, which is an advantage for deciphering spectral mixtures (e.g. soils, rocks, vegetation, and moisture) at this scale. Other important issues for controlling the utility of ASTER images for resolving the spectral characteristics of tropical soils include atmospheric effects (e.g. water vapor, $\mathrm{CO}_{2}$, and aerosols), sensor effects (e.g. crosstalk), and topographic shadowing effects.

The correlation level between the soil spectra and the ASTER pixel spectra was established at corresponding pixel training sites using orthorectified, atmospherically-corrected ASTER imagery (Fig. 9a). Each signature, considering the 9 ASTER bands, was individually compared using regression analysis (Fig. 9). The results demonstrated that regular $\mathrm{R}^{2}$ values oscillated between 0.6493 and 0.7886 , the only exception being the sample containing gibbsite (A4-A1), which showed low $\mathrm{R}^{2}(\sim 0.1361)$ (Fig. 9e). This discrepancy may be attributed either (i) to the presence of small quantities of gibbsite in the area, which could be observed through subtle absorption features centered at AST7 band (Fig. 9f), or (ii) to some alteration of the cover between the sample collection and the ASTER imagery acquisition. In the latter, pixels may be formed by a complex spectral mixture of gibbsite-bearing soils and dry or green vegetation, which produces lignin-cellulose features near $2.26 \mu \mathrm{m}$ (Serbin et al., 2009) (Fig. 9f).

The main kaolinite features and its typical doublet between 2.160 and $2.205 \mu \mathrm{m}$, covered by bands AST5 and AST6, showed analogous behavior both in the ASTER-bandwidth resampled field spectra and in the spectra derived from atmospherically-corrected (reflectance) ASTER image pixels. The correlation analysis of the data resulted in high $R^{2}$ values for samples A6 (0.7886 - Fig. 9d) and A13 (0.6849Fig. $9 \mathrm{~d}$ and e), despite the prominent mixture of materials in the study area (e.g. remaining crops and grasses). For samples 14 and 21 (Fig. 9b and $c$ ), the variation between the depth and inclination of the spectral reflectance between bands AST2 and AST3 due to the abundant iron content (typical inflections between $0.800 \mu \mathrm{m}$ and $0.900 \mu \mathrm{m}$ ) were well reproduced in the spectra extracted from ASTER imagery pixels. These samples showed the highest $R^{2}$ values (0.7245 and 0.6493) (Fig. 9b and c).

\subsection{ASTER soil mapping results}

The Mixture-Tuned Matched Filtering algorithm was used to map the soil spectral characteristics identified in previous sections. This procedure, originally developed for the processing of hyperspectral data, has proven to be effective for ASTER images, especially for mapping targets with high spectral mixture percentage and reduced 
a

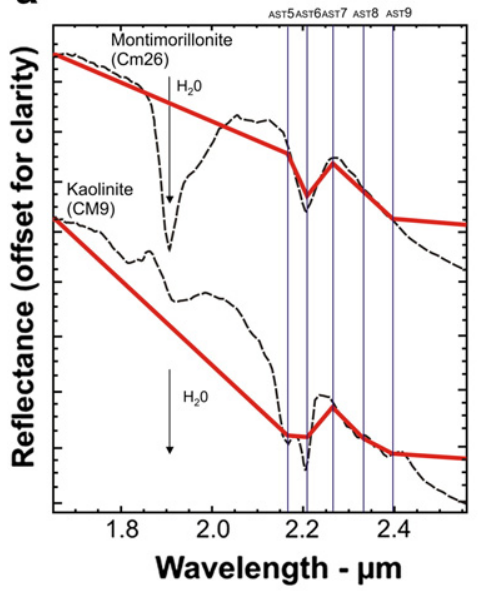

b

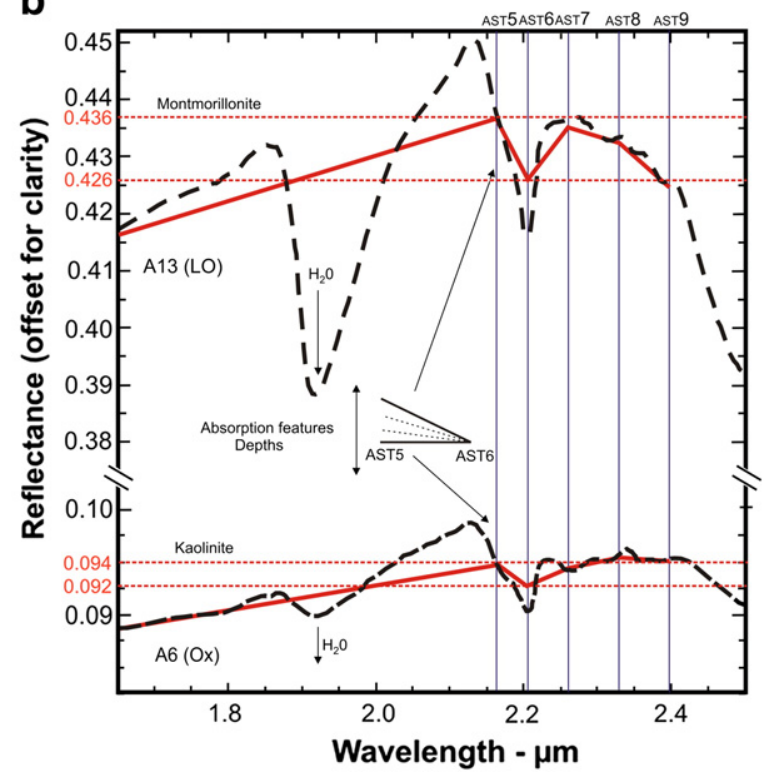

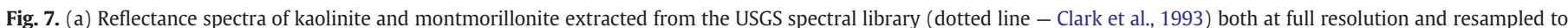

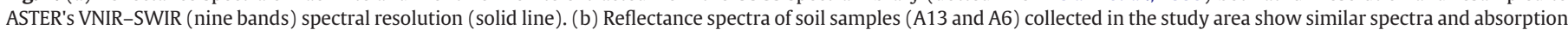

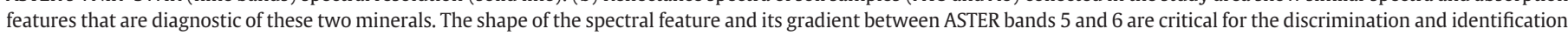
of kaolinite and montmorillonite at such resolution.
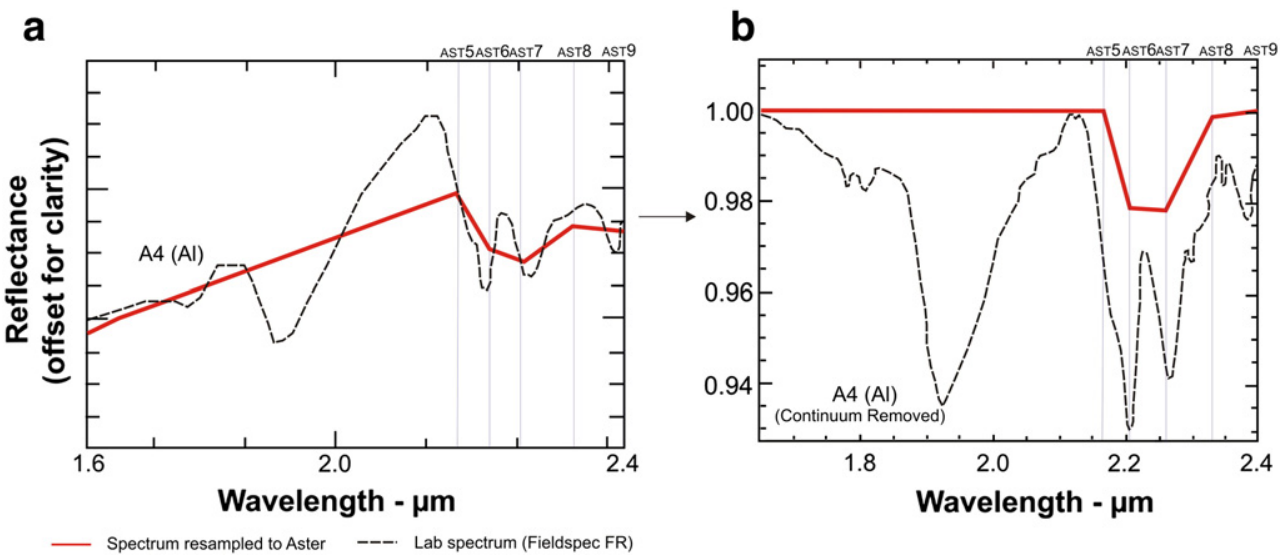

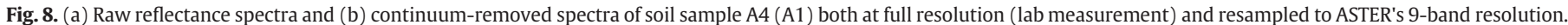
The absorption feature of gibbsite at $2.265 \mu \mathrm{m}$ (b) is highly distinct, despite the prominent content of ferric iron in the sample.

dimensions (e.g. Hubbard \& Crowley, 2005; Souza Filho et al., 2003), characteristics commonly observed in highly anthropized soils and vegetation areas, as well as in our study area. The Matched Filtering (MF) component establishes a n-dimensional measure, such as a vector unit, into average pixel values between 0 and 1, thus providing a MF-score grayscale image in which the background data is centered around 0 and the end-member data occur around 1 (perfect match) as a result. In addition the algorithm produces an Infeasibility grayscale image. The Mixture-Tuned component establishes a standard deviation measure (tridimensional cone) into a n-dimensional scatter plot between MF score and Infeasibility images, eliminating the false positives and providing the end-members with the relative suitability degree (MTMF - ITT, 2009). This algorithm circumvents the mixed pixel modeling's unit-sum and non-negativity mathematical constraints, which occurs in the standard fully constrained spectral unmixing model (Boardman, 1998; Heinz \& Chang, 2001). The MTMF is effectively an unconstrained linear spectral unmixing which is able to estimate the smallest participation of a material in the pixel (subpixel scale), even if the target material is relatively less abundant than other components (Harsanyi \& Chang, 1994; Williams \& Hunt, 2002). This assumption underlies our study, since we assume that the spectral mineralogical characteristics of soils are a complex and subtle mixture of small targets. Besides, MTMF does not require knowledge of all scene fractions, thus providing efficient backgroundminimization effects, and maximizing the response of each single known end-member. In our study, soil end-members are highlighted while active photosynthetic vegetation (APV) composes the background scene (Fig. 10). This approach is highly appropriate to tropical terrains due to the complex canopy-cover variability and the massive domain of green vegetation in these areas.

We used soil reference spectra based on pixels extracted from the ASTER imagery as end-members for the MTMF classification. ASTER

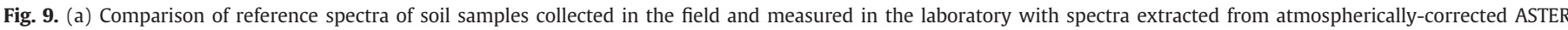

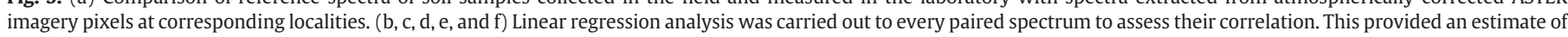
the equivalence between the spectral signatures. 

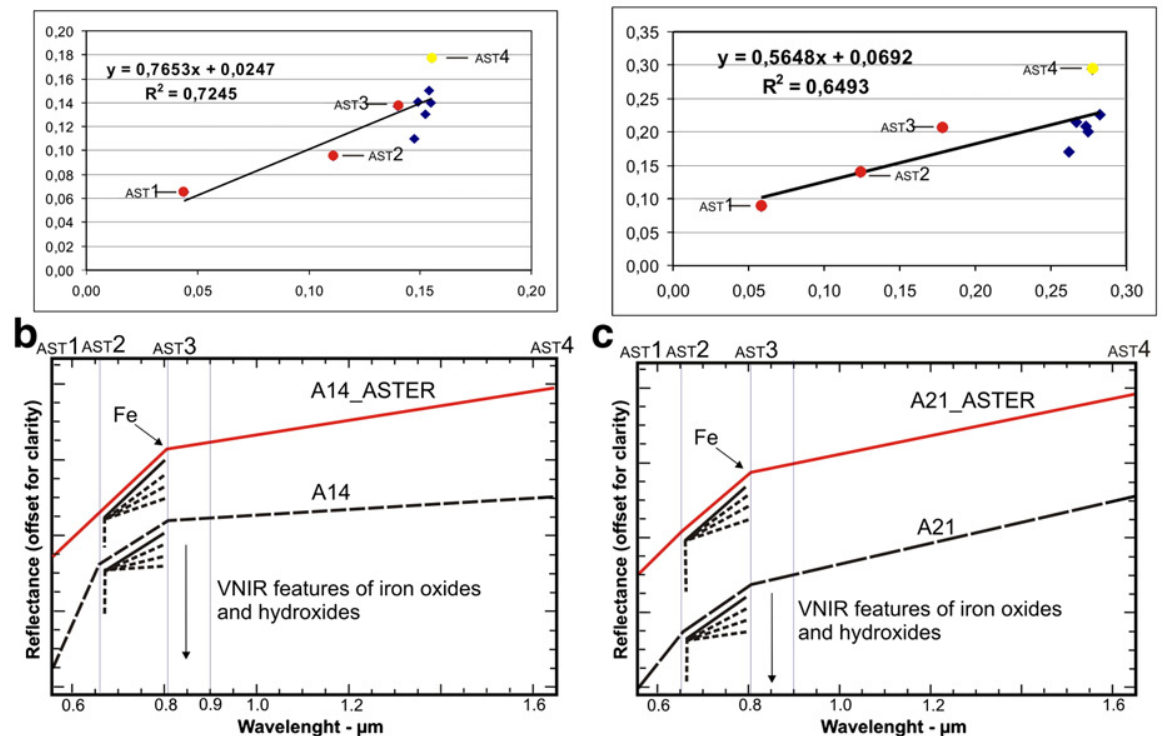

4 C
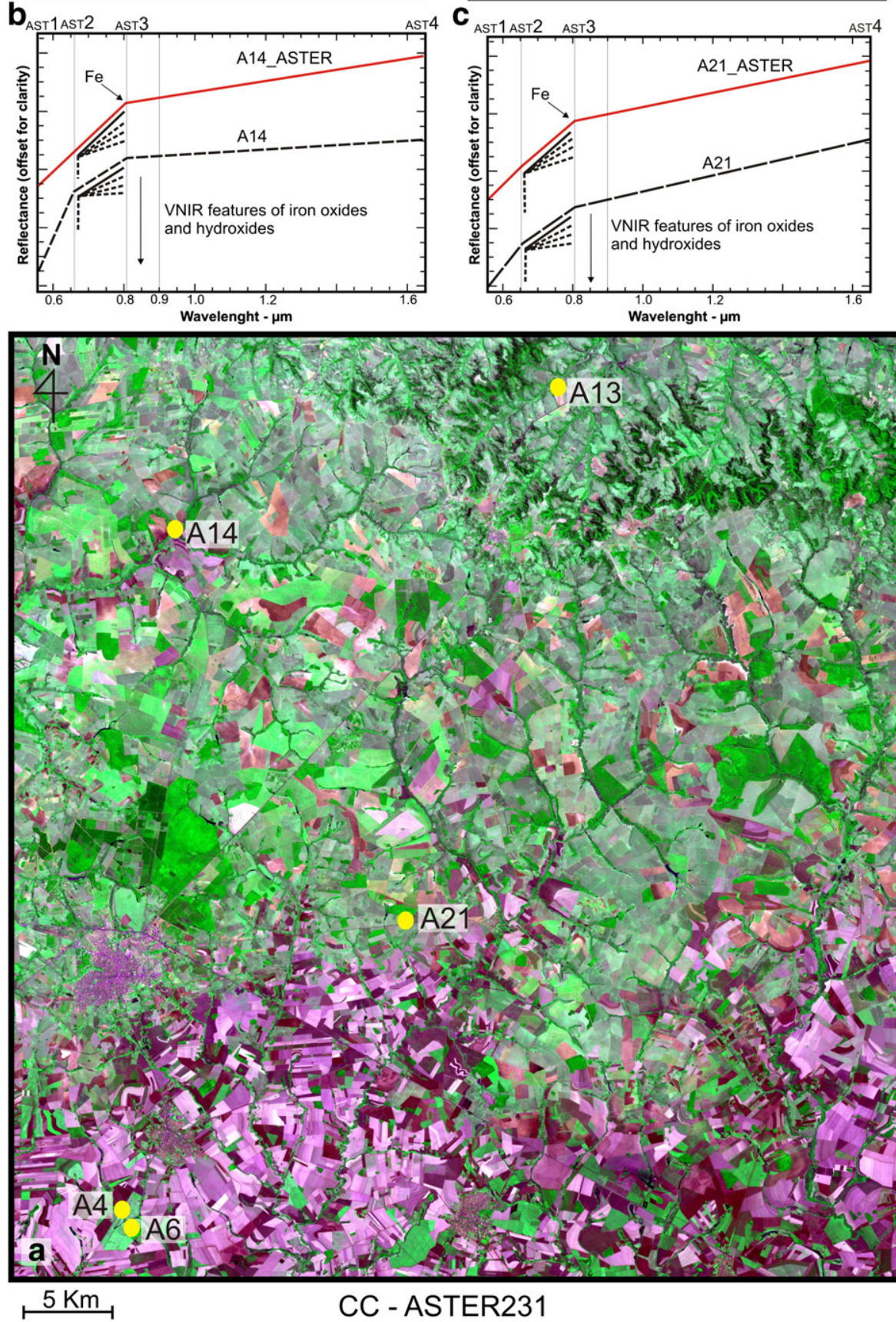

Reference Spectra: Aster Imagery Pixels

Lab spectra: Soil Samples

(resampled to ASTER spectral resolution)

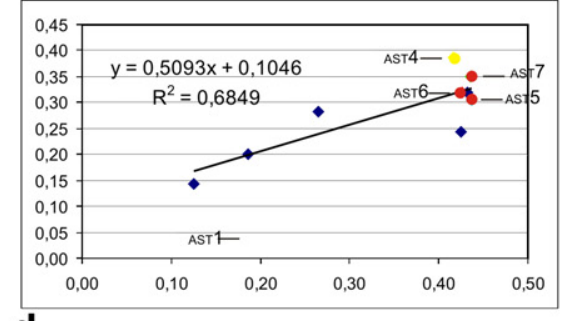

d
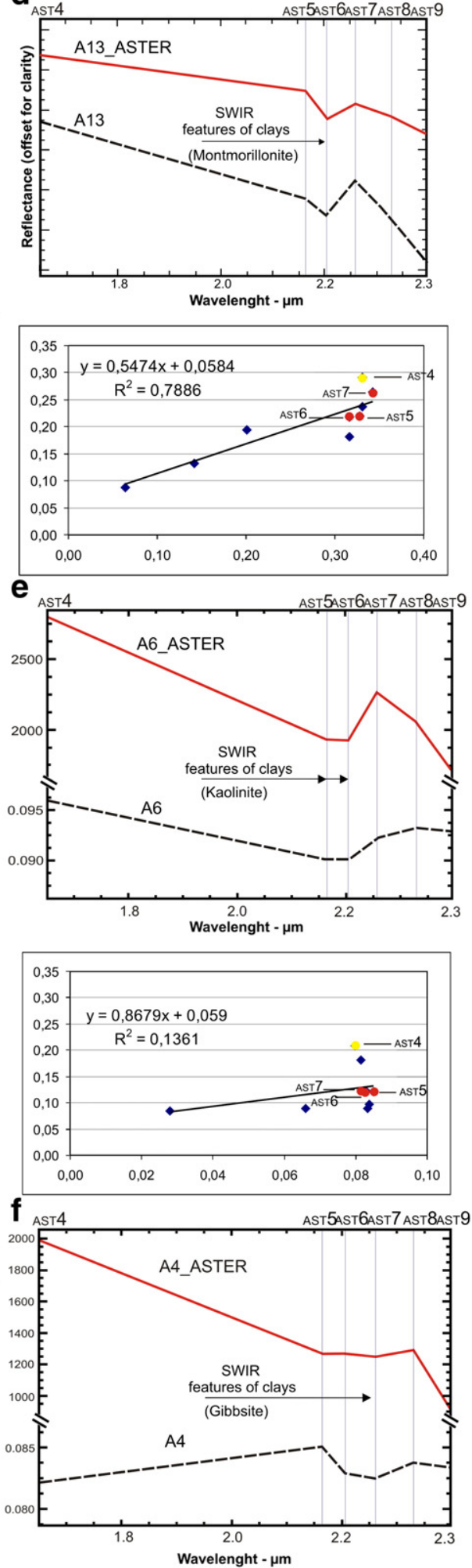


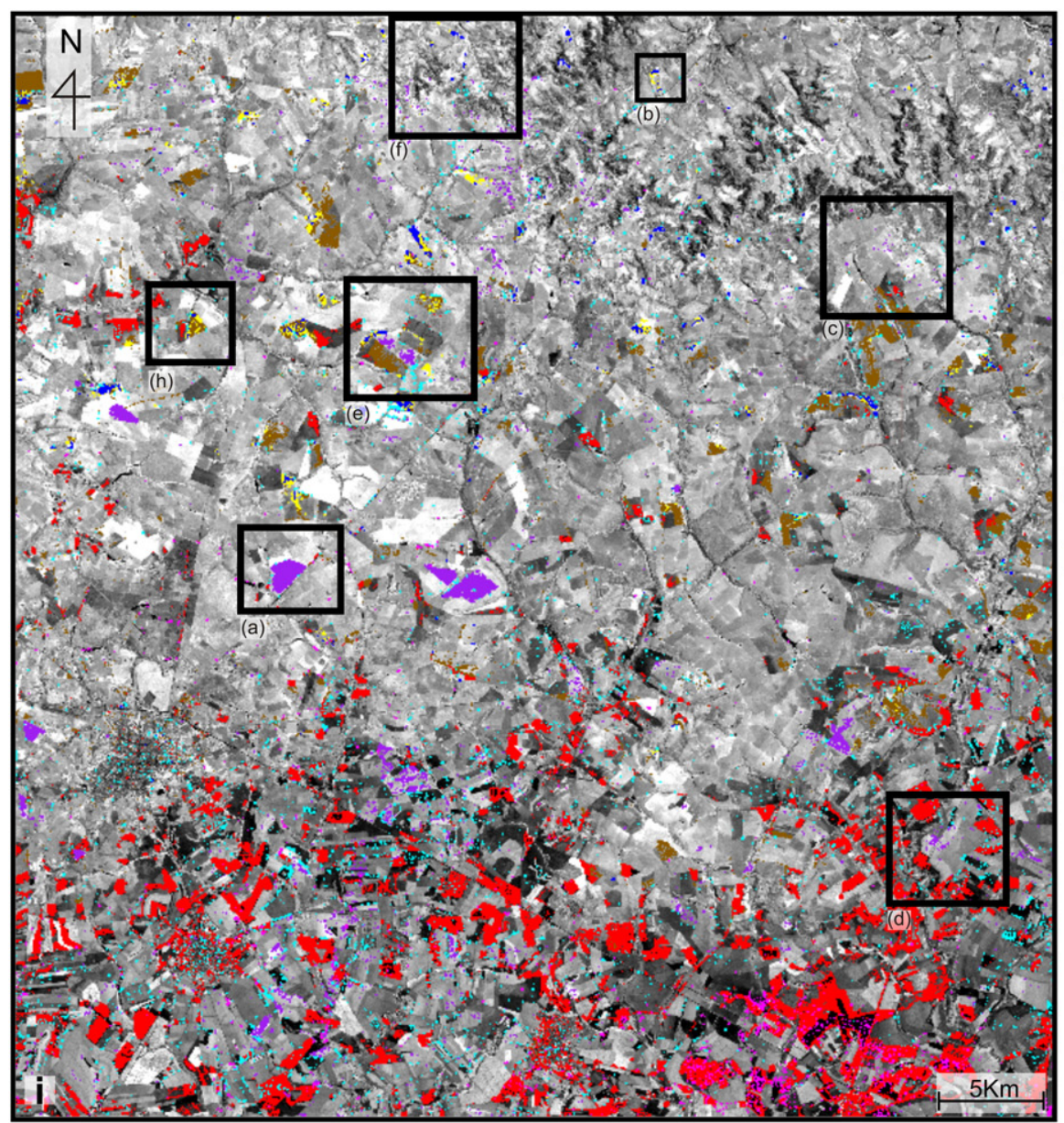

\section{Soils Properties \\ Endmembers Mapped}

$\underset{M E-I 1}{\text { Sandy soil }}$

Iron high abundance $\left(\mathrm{Fe}^{+}\right)$

ME - A14

Iron low abundance (Fe3')

ME - A21

\section{Kaolinite \\ ME - A6}

\section{Montmorillonite \\ ME - A 13}
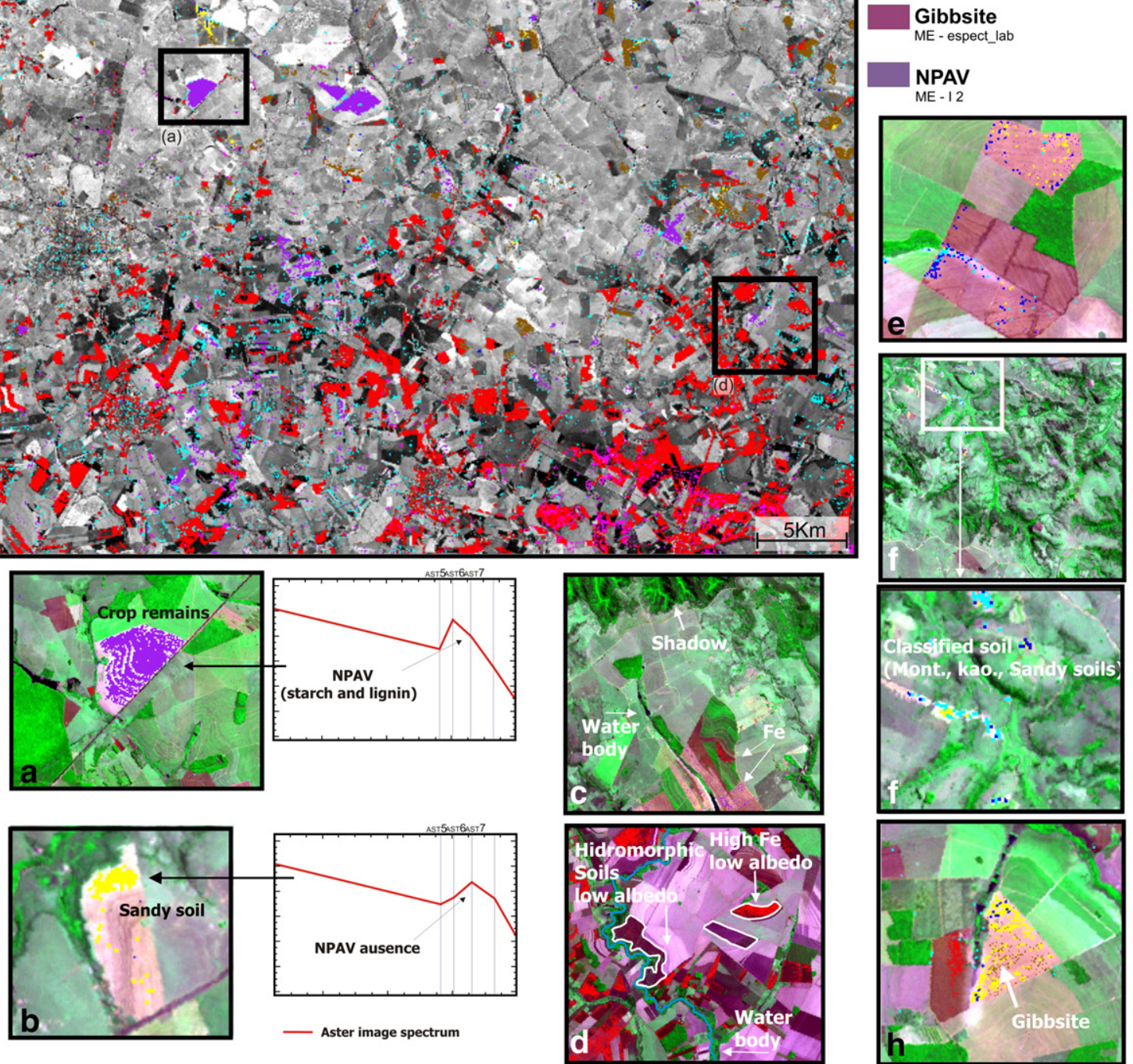

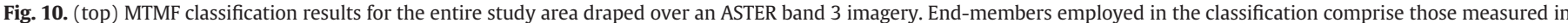

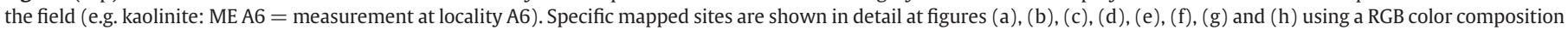
of ASTER bands 231 as background.

bands AST1, AST2, AST3 (VNIR), and AST4 (SWIR) were used for mapping iron oxides and hydroxides, whereas ASTER bands AST4, AST5, AST6, AST7, and AST8 (SWIR) were used separately for mapping clay minerals and/or gibbsite. Two additional image end-members (IEM) were also considered, so that active nonphotosynthetic vegetation (ANPV-IEM 1) could be separated from sandy soils (IEM-2). ANPV is often confused with sandy soil in multispectral orbital imagery due to the high reflectance values showed by both quartz and dry foliage. This fact makes it harder to assess degraded soils in environmental systems, because this type of soil is associated with an intensely erosive processes and poor fertility. The use of ASTER Thermal Infrared bands (TIR - AST10/8.125 $\mu \mathrm{m}$-AST14/10.95 $\mu \mathrm{m}$ ) is highly efficient for this approach, due to its ability to reproduce the main quartz spectral diagnostic feature (reststrahlen bands $-\sim 8.2-9.3 \mu \mathrm{m}$ ) (Vicente \& Souza Filho, 2010). However, ASTER/TIR's 90-m spatial resolution restricts our goals in this work. It is therefore essential to consider ANPV biochemical components in the SWIR region for the separation of these targets in order to obtain a more effective mapping of soil mineral components using ASTER data (Almeida et al., 2006; Serbin et al., 2009). 
Overall, seven different end-members were considered in the MTMF classification: (i) iron-rich soils, (ii) iron-poor soils, (iii) sandy soils, (iv) clayey soils dominated by kaolinite, (v) clayey soils dominated by montmorillonite, (vi) clayey soils containing gibbsite, and (vii) ANPV.

The MTMF classification helped separate active photosynthetic vegetation (APV), sandy soil and active nonphotosynthetic vegetation (ANPV) based on the different spectral characteristics of each endmember at the subpixel scale. This observation is confirmed in great detail in Fig. 10, where crop remnants are displayed as lilac-colored pixels (Fig. 10a), whereas sandy soils were classified and displayed as yellow-colored pixels (Fig. 10b). Reflectance variations in bands AST6 (2.185-2.225 $\mu \mathrm{m})$ and AST7 $(2.235-2.285 \mu \mathrm{m})$ confirm the presence of NPAV. This was mainly due to the detection of "dry material" derived from generic biochemical compounds (amides, lignin and cellulose) as well as the loss of water from broad-leafed structures $(\sim 2.150-2.350 \mu \mathrm{m})$ (Serbin et al., 2009; Zagolski et al., 1996).

Soils with high contents of ferric iron display attenuated reflectance throughout the VNIR-SWIR range, and are usually associated with low-albedo areas in the imagery and marked by masked spectral features (Clark, 1999; Stoner \& Baumgardner, 1981). This combination sometimes results in ambiguous classifications. Targets with low albedo related to topographic shadows, water bodies, moisture or organic soils can be erroneously classified as ironrich surfaces (Robinove et al., 1981). A similar situation is shown in Fig. 10c and d, with areas with hydromorphic soils close to water bodies (Fig. 10d) and shadows caused by a rough relief (Fig. 10c). These areas all appear as dark shades of colors in a false-color composite image of ASTER bands 231 (RGB), due to low albedo. Interestingly, these sites and neighboring areas were not mapped by the MTMF algorithm as being highly abundant in iron (red-colored pixels - Fig. 10).

Kaolinite is commonly associated with intense weathering and leaching processes as well as pedogenetic formation in tropical soils (Allen \& Hajek, 1989; EMBRAPA, 1999), which explains its dominant presence in well-developed soils in the southern sector of our study area (cyan-colored pixels - Fig. 10i). The occurrence of montmorillonite is associated with younger soils that are less profound in extent, mainly in the N-NW sector (blue pixels - Fig. 10i). Although these are two common clay minerals that are subject to typical masking effects of amorphous iron in soils that have undergone intense intemperism (Formaggio et al., 1996), the presence of both can be identified in areas of rough relief, such as cuestas, in the north of the image (Fig. 10f).

The presence of gibbsite appears to be rare and occurs predominantly in Oxisols in the study area (purple pixels in Fig. 10h). Identification of gibbsite proved possible, even though iron-rich soils and dry vegetation materials (Serbin et al., 2009) tend to mask its typical absorption features. Gibbsite mapped at these sites seems to be associated with exposure of ancient surfaces. Therefore, the presence of this mineral may be an important indicator of soil weathering age.

In general, the spectral mapping of the study area also indirectly revealed bedrock lithology, considering the intrinsic relation between soils and their geologic substrates. Younger soils, rich in kaolinite and montmorillonite, were found at higher altitudes in the north of the area, which comprises Adamantine and Marília Formation rocks (mainly derived from sandy sediments). To the south, at lower altitudes (Paranapanema river basin), soils were derived from the weathering of basaltic rocks of the Serra Geral Formation, which is characterized by a high concentration of iron oxides and hydroxides, as well as gibbsite.

\section{Conclusion}

Reflectance spectroscopy made it possible to assess the capacity of ASTER data for reproducing diagnostic spectral features of tropical soils, taking into consideration their mineralogy components and granulometry. A comparative analysis of the six reference cover types observed in the study area (i.e. iron-rich soils, iron-poor soils, sandy soils, kaolinite-rich soils, montmorillonite-rich soils, and ANPV) demonstrated high correlation between spectra derived from field samples and those derived from ASTER image pixels converted to reflectance, with $R^{2}$ values ranging between 0.6493 and 0.7886 .

Considering the VNIR region ( 0.52 to $0.86 \mu \mathrm{m}$ ), it was possible to establish the relative abundance of iron oxides/hydroxides in the soil based on typical spectral inflections between 0.80 and $0.90 \mu \mathrm{m}$, as well as overall signatures in ASTER AST2 and AST3 bands. In the SWIR region (1.6 to $2.430 \mu \mathrm{m})$, exploration of the spectral diagnostic features of kaolinite, montmorillonite and gibbsite (2.160$2.265 \mu \mathrm{m}$ ) enabled the remote mapping based on spectral features resolved by ASTER bands AST5, AST6 and AST7. The position of the SWIR bands also helped separate ANPV, APV and bare soils that presented diagnostic spectral variations in AST6, AST7 and AST8 bands. These signatures were successfully mapped based on the MTMF classification algorithm, despite some topographic variations and spectral mixture of targets caused by intense local land use.

The results achieved here for the tropical terrains of the Assis region (SE Brazil) could easily be extended to other sites with similar characteristics, considering equivalent data and methods.

\section{References}

Abrams, M., \& Hook, S. J. (1995). Simulated ASTER data for geological studies. IEEE Transactions on Geoscience and Remote Sensing, 33, 629-699.

ACORN (2002). ACORN 4.0 tutorial: EUA, AGI-Colorado 109 pp.

Allen, B. L., \& Hajek, B. F. (1989). Mineral occurrence in soil environments. Minerals in soils environments, $n .1$ (pp. 199-278). (2nd ed). Wisconsin: Soil Science Society of America.

Almeida, T. I. R., Souza Filho, C. R., \& Rosseto, R. (2006). ASTER and landsat ETM+ images applied to sugarcane yield forecast. International Journal of Remote Sensing, 19, 4057-4069.

Arsenault, E., \& Bonn, F. (2005). Evaluation of soil erosion protective cover by crop residues using vegetation indices and spectra mixture analysis of multispectral and hyper spectral data. CATENA, 62, 157-172.

ASD - Analytical Spectral Devices (1999). FieldSpec FR - user's guide. 89 pp.

Asner, G. P., \& Lobell, D. B. (2000). A biogeophysical approach for automated SWIR unimixing of soils and vegetation. Remote Sensing of Environment, 74, 99-112.

Ben-Dor, E., Inbar, Y., \& Chen, Y. (1997). The reflectance spectra of organic matter in the visible near infrared and short wave infrared region (400-2500 nm) during a controlled decomposition process. Remote Sensing of Environment, 61, 1-15.

Ben-Dor, E., Irons, J. A., \& Epema, A. (1998). Soil spectroscopy. In A. Rencz (Ed.), Manual of remote sensing (pp. 111-189). (3rd ed). New York: J. Wiley and Sons Inc.

Boardman, J. W. (1993). Automated spectral unmixing of AVIRIS data using convex geometry concepts. Annual JPL Airborne Geosciences Workshop, 4, Pasadena, CA. Summaries. JPL Publ., 93-26. (pp. 11-14).

Boardman, J. W. (1998). Leveraging the high dimensionality for AVIRIS data for improved sub-pixel target unmixing and rejection of false positives: Mixture-tuned matched filtering. Seventh JPL Airborne Earth Science Workshop, January 12-16, Summaries. JPL Publ., 97-21. (pp. 1).

Boardman, J. W., \& Kruse, F. A. (1994). Automated spectral analysis: A geologic example using AVIRIS data, north Grapevine Mountains, Nevada. ERIM Tenth Thematic Conference on Geologic Remote Sensing, 10. Proceedings, 1. (pp. 407-418) Ann Arbor, MI: Environmental Research Institute of Michigan.

Boardman, J. W., Kruse, F. A., \& Green, R. O. (1995). Mapping target signatures via partial unmixing of AVIRIS data. In: Summaries, Fifth JPL Airborne Earth Science Workshop, JPL Publication 95-1, 1, 23-26.

Brady, N. C. (1989). Natureza e propriedades dos solos.Rio de Janeiro: Freitas Bastos 878 pp.

Buckingham, W. F., \& Sommer, S. E. (1983). Mineralogical characterization of rock surfaces formed by hydrothermal alterations and weathering - Application to remote sensing. Economic Geology, 78, 664-674.

Chabrillat, S., Goetz, A. F. H., Krosley, L., \& Olsen, H. W. (2002). Use of hyper spectral images in the identification and mapping of expansive clay soils and role spatial resolution. Remote Sensing of Environment, 82, 431-445.

Chang, C. W., Laird, D. A., Mausbach, M. J., \& Hurburgh, C. R. (2001). Near-infrared reflectance spectroscopy - Principal components regression analyses of soil properties. Soil Science Society of American Journal, 65, 480-490.

Clark, R. N. (1999). Spectroscopy of rock and minerals, principles of spectroscopy. In A. Rencz (Ed.), Manual of remote sensing (pp. 3-58). (3rd ed). New York: J. Wiley and Sons Inc.

Clark, R. N., \& Roush, T. L. (1984). Quantitative analysis techniques for remote sensing applications. Journal of Geophysical Research, 89(B7), 6329-6340.

Clark, R. N., Swayze, G. A., Gallagher, A., King, T. V. V., \& Calvin, W. M. (1993). The U.S. geological survey digital spectral library: Version 1: 0.2 to $3.0 \mathrm{um}$. USGS Open File Report 93-592. : U.S. Geological Survey 1340 pp. 
Coleman, T. L., Agbu, P. A., \& Montgomery, O. L. (1993). Spectral differentiation of surface soils and soils properties. Is it possible from space platforms? Soil Science Society of American Journal, 155, 283-293.

Crowley, J. K., \& Vergo, N. (1988). Near-infrared reflectance spectra of mixtures of kaolin-group minerals: Use in clay mineral studies. Clays and Clay Minerals, 36 , $310-316$.

Demattê, J. L. I., \& Holowaychuck, N. (1977). Solos da região de São Pedro, Estado de São Paulo: II mineralogia (1). Revista Brasileira de Ciência do Solo, 1, 99-103.

Ducart, D. F., Crósta, A. P., Souza Filho, C. R., \& Coniglio, J. (2006). Alteration mineralogy at the Cerro La Mina epithermal prospect, Patagonia, Argentina: Field mapping, short-wave Infrared spectroscopy, and ASTER images. Economic Geology and the Bulletin of the Society of Economic Geologists, 101, 981-996.

EMBRAPA - Empresa Brasileira de Pesquisa Agropecuária/Centro Nacional de Pesquisa de Solos (1999). Rio de Janeiro.Sistema Brasileiro de Classificação de Solos. Brasília: SPI $412 \mathrm{pp}$.

Epiphanio, J. C. N., Formaggio, A. R., Valeriano, M. M., \& Oliveira, J. B. (1992). Comportamento espectral de solos do Estado de São Paulo. São José dos Campos: INPE 5424 PRP/172. 132 pp.

ERSDAC - Earth remote sensing data analysis center (2001). The crosstalk correction software: User's guide.: Mitsubishi Space Software Co. Ltd. 17 pp.

Foley, J. A., DeFries, R., Asner, G. P., Barford, C., Bonan, G., Carpenter, S. R., et al. (2005). Global consequences of land use. Science, 309, 570-574.

Formaggio, A. R., Epinhanio, J. C. E., Valeriano, M. M., \& Oliveira, J. B. (1996). Comportamento espectral $(450-250 \mathrm{~nm})$ de solos tropicais de São Paulo. Revista Brasileira de Ciência do Solo, Campinas, 20, 467-474.

Fraser, S. J. (1991). Discrimination and identification of iron oxides using satellite thematic mapper data: A Newman case study. International Journal of Remote Sensing, 12, 635-641.

Galvão, L. S., Almeida-Filho, R., \& Ícaro, V. (2005). Spectral discrimination of hydrothermally altered materials using ASTER short-wave infrared bands: Evaluation in a tropical savannah environment. International Journal of Applied Earth Observation and Geoinformation, 7, 107-114.

Green, A. A., Bermam, M., Switzer, P., \& Craig, M. D. (1988). A transformation for ordering multiespectral data in terms of image quality with implications for noise removal. IEEE Transactions on Geosciences and Remote Sensing, 26(1), 65-74.

Grove, C. I., Hook, S. J., \& Paylor, E. D., II (1995). Laboratory reflectance spectra of 166 minerals 0.4 to 2.5 micrometer. Jet Propulsion Laboratory (JPL) Publ., 92-2, Pasadena, CA: California Institute of Technology.

Harsanyi, J. C., \& Chang, C. (1994). Hyperspectral image classification and dimensionality reduction: An orthogonal subspace projection approach. IEEE Transactions on Geoscience and Remote Sensing, 32, 779-785.

Heinz, D. C., \& Chang, C. (2001). Fully constrained least squares linear spectral mixture analysis method for material quantification in hyperspectral imagery. IEEE Transactions on Geoscience and Remote Sensing, 39, 529-545.

Hubbard, B. E., \& Crowley, J. K. (2005). Mineral mapping on the Chilean-Bolivian Altiplano using co-orbital ALI, ASTER and Hyperion imagery: Data dimensionality issues e solutions. Remote Sensing of Environment, 99, 173-186.

Hunt, G. R., \& Salisbury, J. W. (1971). Visible and near infrared spectra of minerals and rocks: II Carbonate. Modern Geology, 2, 23-30.

Hunt, G. R., Salisbury, J. W., \& Lenhoff, C. J. (1971). Visible and near infrared spectra of minerals and rocks: III oxides and hydroxides. Modern Geology, 2, 195-295.

IAC - Instituto Agronômico de Campinas. (1999). Mapa pedológico do Estado de São Paulo, $1: 500000$

IBGE - Instituto Brasileiro de Geografia e Estatística. (CIM). (2004). Base Cartográfica Integrada Digital do Brasil ao Milionésimo, 1:1,000,000.

IPT - Instituto de Pesquisas Tecnológicas. (1981). Mapa geomorfológico do estado de São Paulo, 1:500,000.

ITT - Visual Information Solutions (2009). User's manual for ENVI 4.7. 720 pp.

Iwasaki, A., \& Tonooka, H. (2005). Validation of a crosstalk correction algorithm for ASTER/SIWR. IEEE Transactions on Geoscience and Remote Sensing, 43, 2747-2751.

Kruse, F. A., Thiry, M., \& Hauff, P. L. (1991). Spectral identification (1,2-2,5 $\mu \mathrm{m})$ and characterization of Paris Basin kaolinite/smectite clays using a field spectrometer. International Colloquium - Physical measurements and signatures in remote sensing, 5, Courchevel, France. Proceedings: INRA (pp. 181-184).

Lobell, D. B., \& Asner, G. P. (2002). Moisture effects on soil reflectance. Soil Science Society of America Journal, 66, 722-727.
Madeira Netto, J. S., Pouget, M., Bedidi, A., \& Cervelle, B. (1991). Relations entre lês constituants minéraux d'oxisols brésiliens el leurs signatures spectrales du visible a l'infraruge moyen: application a des données satellitaires (Landsat TM). I. Les oxydes de fer. II. La kaolinite at la gibbsite, implications sur la texture. Journeés de télédétection, 2,1990. Caractérisation et suivi des milieux terrestres en regions arides et tropicales, 1991 (pp. 21-25).

Morra, M. J., Hall, M. H., \& Freeborn, L. L. (1991). Carbon and nitrogen analysis of soils fractions using near infrared reflectance spectroscopy. Soil Science Society of America Journal, 55, 288-291.

Nanni, M. R., \& Demattê, J. A. N. (2006). Spectral reflectance methodology in comparison to traditional soil analysis. Soil Science Society of America Journal, 70, 393-407.

Poesen, J. W. A., \& Nearing, M. A. (1993). Soil surface sealing and crusting. Catena Supplement, $n^{\circ} .24139 \mathrm{pp}$.

Robinove, C. J., Chavez, P. S., Gehring, D., \& Holmgren, R. (1981). Arid land monitoring using Landstat albedo difference images. Remote Sensing of Environment, 11, $133-156$.

Sawhney, B. L. (1989). Interstratification in layer silicates. Minerals in soils environments, 1 (pp. 789-824). (2nd ed). Wisconsin: Soil Science Society of America.

Senna, J. A., Souza Filho, C. R., \& Angelica, R. S. (2008). Characterization of clays used in the ceramic manufacturing industry by reflectance spectroscopy: An experiment in the São Simão ball-clay deposit, Brazil. Applied Clay Science, 41, 85-98.

Serbin, G., Daughtry, G. S. T., Hunt, E. R., Jr., Reeves, J. B., III, \& Brown, D. J. (2009) Effects of soil composition and mineralogy on remote sensing of crop residue cover Remote Sensing of Environment, 13, 224-238.

Shepherd, K. D., \& Walsh, M. G. (2002). Development of reflectance libraries for characterization of soil properties. Soil Science Society of America Journal, 66, 988-998.

SMA - Secretaria do Meio Ambiente - (IF) Instituto Florestal/Biota-FAPESP (2002). Levantamento da cobertura vegetal do Estado de São Paulo. : Base cartográfica digital.

Souza Filho, C. R., Tápia, C. H., Crósta, A. P., \& Xavier, R. P. (2003). Infrared spectroscopy and ASTER imagery analysis of hydrothermal alteration zones at the Quellaveco Porphyry-Cooper Deposit, Southern Peru. Proceedings of the American Society of Photogrammetry and Remote Sensing (ASPRS), Annual Conference - "Technology: Converging at the Top of the World" (pp. 1-12).

Stoner, E. R., \& Baumgardner, M. F. (1981). Characteristic variations in reflectance of surface soils. Soil Science Society of America Journal, 45, 1161-1165.

Stoner, E., Derksen, I., \& Macedo, J. (1991). Discriminação espectral de Latossolos do Planalto Central brasileiro. Pesquisa Agropecuária Brasileira, 26, 1599-1606.

Sumner, M. E., \& Stewart, B. E. (1992). Soil crusting: Chemical and physical properties. Boca Raton: Lewis Publishers, CRC Press, Inc 372 pp.

Thompson, A. J. B., Phoebe, L. H., \& Audrey, J. R. (1999). Alteration mapping in exploration: Application of short-wave infrared (SWIR) spectroscopy. Society of Economic Geologist, Newsletter, 39, 1-27.

Tilman, D., \& Lehman, C. (2001). Human-caused environmental change: Impacts on plant diversity and evolution. Proceedings of the National academy of Sciences of the United States of America Colloquium Paper, 98(10), 5433-5440.

Valeriano, M. M., Epiphanio, J. C. N., Formaggio, A. R., \& Oliveira, J. B. (1995). Bidirectional reflectance factor of 14 soil classes from Brazil. International Journal of Remote Sensing, 35, 113-128.

Velde, B. (1992). Introduction to clay minerals.London: Chapman \& Hall 198 pp.

Vicente, L. E., \& Souza Filho, C. R. (2010). Detecção de Quartzo e Argilominerais para o Monitoramento de Degradação de Terras a partir de dados do Infravermelho Termal do Sensor ASTER. Brazilian Journal of Geophysics, 28, 229-247.

Vicente, L. E., Souza Filho, C. R., \& Perez Filho, A. (2005). Mapeamento de formações arenosas em fragmentos de Cerrado utilizando dados e produtos do sensor ASTER Simpósio Brasileiro de Sensoriamento Remoto, Goiânia, INPE/SELASR. 12 (pp. 3419-3426). $<<$. http://www.ltid.inpe.br/sbsr2005 >>.

Williams, A. P., \& Hunt, E. R., Jr. (2002). Estimation of leafy spurge cover from hyperspectral imagery using mixture tuned matched filtering. Remote Sensing of Environment, 82, 446-456.

Zagolski, F., Pinel, V., Romier, J., Alcayde, D., Fontanaru, J., Gastellu-Etchegorry, J. P., et al. (1996). Forest canopy chemistry with high spectral resolution remote sensing. International Journal of Remote Sensing, 17, 1107-1128. 